NBER WORKING PAPER SERIES

\title{
HETEROGENEOUS ECONOMIC RETURNS TO POSTSECONDARY DEGREES: EVIDENCE FROM CHILE
}

\author{
Loreto Reyes \\ Jorge Rodríguez \\ Sergio S. Urzúa \\ Working Paper 18817 \\ http://www.nber.org/papers/w18817
}

\author{
NATIONAL BUREAU OF ECONOMIC RESEARCH \\ 1050 Massachusetts Avenue \\ Cambridge, MA 02138 \\ February 2013
}

We are indebted to the useful comments of Samuel Berlinksy, Matias Busso, Judy Hellerstein, Giordano Palloni, Ricardo Mayer, Rodrigo Montero, Claudia Sanhueza, Miguel Sarsoza, Ken Ueda, and the seminar participants at Universidad Diego Portales (January, 2012) and IADB (March, 2012). A previous version of this paper circulated under the title "The Economic Returns to Postsecondary Degrees in Chile". We thank the Ministry of Finance of Chile for providing us access to the data. The authors did not have access to information leading to the identication of individuals. The data analysis was carried out in a secure server. Sergio Urzúa thanks the support of Centro de Microdatos at the University of Chile through the Millennium Science Initiative sponsored by the Chilean Ministry of Economics, Development and Tourism, Project NS100041. The views expressed herein are those of the authors and do not necessarily reflect the views of the National Bureau of Economic Research.

NBER working papers are circulated for discussion and comment purposes. They have not been peerreviewed or been subject to the review by the NBER Board of Directors that accompanies official NBER publications.

(C) 2013 by Loreto Reyes, Jorge Rodríguez, and Sergio S. Urzúa. All rights reserved. Short sections of text, not to exceed two paragraphs, may be quoted without explicit permission provided that full credit, including $\odot$ notice, is given to the source. 
Heterogeneous Economic Returns to Postsecondary Degrees: Evidence from Chile Loreto Reyes, Jorge Rodríguez, and Sergio S. Urzúa

NBER Working Paper No. 18817

February 2013

JEL No. C25,C38,I21,I24,J24

\begin{abstract}
$\underline{\text { ABSTRACT }}$
We analyze the economic returns to different postsecondary degrees in Chile. We posit a schooling decision model with unobserved ability, observed test scores and labor market outcomes. We benefit from administrative records to carry out our empirical strategy. Our results show positive average returns to postsecondary degrees, especially for five-year degrees. However, we also uncover a large fraction of individuals with realized negative net returns. Although psychic benefits of postsecondary education could rationalize this result, we argue this might also suggest that individuals lack information at the time schooling decisions are made. Finally, our findings illustrate the importance of allowing for heterogeneous treatment effects when making policy recommendations.
\end{abstract}

Loreto Reyes

Ministry of Finance, Chile

Teatinos 120, Piso 12

Santiago, Chile

lreyes@hacienda.gov.cl

Jorge Rodríguez

University of Chicago

1126 East 59th Street

Chicago, Illinois 60637

jorger@uchicago.edu
Sergio S. Urzúa

Department of Economics

University of Maryland

3105 Tydings Hall \#3115C

College Park, MD 20742

and NBER

urzua@econ.umd.edu 


\section{Introduction}

The vast evidence suggesting average positive returns to postsecondary education has contributed to the rapid worldwide expansion of the higher education sector. ${ }^{1}$ However, concerns about the weak labor market performance of recent college graduates in developed and developing countries, uncertainty about the quality of institutions of higher education, the climbing tuition costs, and the accumulation of large student debts are challenging the presumption that a postsecondary degree confers financial security. ${ }^{2}$ In this paper, we analyze this phenomenon by estimating heterogeneous treatment effects within and across postsecondary degrees using data from Chile. Our intuition is simple: investing in higher education can deliver positive average returns, while still yielding a negative economic return for many individuals.

We study Chile's highly competitive postsecondary education system. Our empirical model allows observationally equivalent individuals to face different returns to education depending on their unobserved endowments. Chile is particularly interesting because until recently its schooling system was regarded a success. However, over the past few years the system has received criticisms form a number of different sources. Many of the criticisms could also be applied to the postsecondary educational system in a variety of developed and developing countries.

This paper contributes to the literature analyzing the returns to education in the context of models with unobserved heterogeneity (Willis and Rosen, 1979; Card, 1993, 2001; Kane and Rouse, 1995; Taber, 2001; Heckman, Urzua, and Vytlacil, 2006; Carneiro, Heckman, and Vytlacil, 2011). It also contributes to the literature estimating schooling choices in complex

\footnotetext{
${ }^{1}$ Between 1998 and 2010, the number of students in tertiary education increased by $53 \%$ in the United States, 46\% in Australia, 65\% in Mexico (source: OECD). In China the figure has soared to more than 31 millions in 2010, up from 23 million students in 2005 (source: National Bureau of Statistics of China), with the numbers of private universities increasing from 20 in 1997 to 630 in 2010 (source: Center for International Higher Education at Boston College).

${ }^{2}$ In 2010 the unemployment rate among recent college graduates in the US ranged between 5.4 and $13.9 \%$. The large dispersion can be explained by major, illustrating the potential risk of unemployment (source: American Community Survey, 2009 and 2010). In China, 6.4\% of the urban population between the ages of 21 and 25 with an undergraduate degree or higher were unemployed (source: Chinese Household Finance Survey Center of Chengdus Southwestern University of Finance and Economics). Average published tuition and fees at public four-year colleges and universities in the US increased by $31 \%$ beyond the rate of inflation over the five years from 2002 to 2007, and by another $27 \%$ between 2007 and 2012 (source: The College Board, Annual Survey of Colleges; NCES, IPEDS). Finally, two-thirds of U.S. college seniors graduated in 2011 with an average student loan debt of $\$ 26,600$, a $5.3 \%$ increase relative to 2010 (source: Project on Student Debt).
} 
settings (Kane, 1996, 1999; Keane and Wolpin, 1997; Cameron and Heckman, 1998). While a few prior studies have analyzed the economic returns to tertiary education in developing countries, our approach represents a significant improvement from previous work in three critical dimensions. ${ }^{3}$ First, we explicitly model the schooling decision of high school graduates over all available educational alternatives. We assume individuals decide on a type of postsecondary degree using an unordered discrete choice model. Second, our model allows for the presence of unobserved heterogeneity, which is interpreted as unobserved ability. More precisely, we assume that schooling decisions depend on an individual's observed characteristics and latent ability (Heckman, Stixrud, and Urzua, 2006; Urzua, 2008). We also investigate the role of short-term credit constraints within this framework. Third,

our results show the importance of understanding the structure of the economic agent's schooling decision process when determining the returns to education (Card, 2001; Heckman, Lochner, and Todd, 2006; Heckman, Urzua, and Vytlacil, 2008). We estimate returns to postsecondary degrees while taking into account the structure of the underlying schooling decision model. In particular, we generate two different returns for each type of postsecondary degree. First, we compare the economic benefits of each postsecondary degree to those obtained when not continuing to postsecondary studies. We also exploit the structure of our schooling choice model to compare the returns to each type of degree with the predicted returns to the second-best alternative We document large heterogeneity for both types of returns.

The empirical strategy is implemented with longitudinal data containing administrative information from several sources. Our initial sample contains information on the universe of graduates from higher education institutions in Chile in 2008. We integrate this data with information from the national college admission system (2001-2007) which contains rich information on test scores and individual demographic and socio-economic variables. Finally, we observe each student's labor market outcomes through 2011 using administrative registers of earnings.

Our main results can be summarized as follows:

\footnotetext{
${ }^{3}$ For a review of evidence on returns to education in Latin America see Behrman, Birdsall, and Szekely (2007); Manacorda, Sanchez-Parama, and Schady (2010); Lustig and Lopez-Calva (2010); Bassi, Busso, Urzua, and Vargas (2012). For Chile see Arellano and Braun (1999); Sapelli (2003); Contreras, Melo, and Ojeda (2005); Meller and Rappoport (2006); Meller (2010); Rau (2013).
} 
1. We find substantial heterogeneity in the returns to postsecondary degrees. We show that the average economic returns to five-year postsecondary degrees are highest among all the available alternatives. However, a significant fraction of individuals face negative net returns: between $35 \%$ and $42 \%$ depending on the type of degree and institution. These individuals would have been financially better off if choosing not to attend tertiary education. The likelihood of observing negative returns is higher when analyzing the return that compares the first-best versus the second-best option. Furthermore, our findings indicate that, conditional on type of degree, individuals endowed with larger stocks of unobserved ability obtain higher economic returns relative to lower ability individuals. Also, we find that individuals with higher latent ability are more likely to enroll in institutions with higher labor market returns.

2. We use our model to carry out policy simulations. In particular, we analyze the effects of a reduction in postsecondary tuition costs. We find that a $10 \%$ reduction in all tuition costs has minimal impact on overall enrollment, but it produces important composition effects. This confirms the importance of allowing for heterogeneity between types of postsecondary degrees. Furthermore, the small change in overall employment suggests that short-term financial constraints might not be binding in the Chilean case. This result is consistent with evidence for the United States (Cameron and Heckman, 2001; Carneiro and Heckman, 2002), but is new in the context of developing countries.

3. We provide empirical evidence that sources of observed and unobserved heterogeneity must be understood and treated as distinct but connected phenomena (Hansen, Heckman, and Mullen, 2004; Heckman, Stixrud, and Urzua, 2006). Indeed, we show that the sorting patterns into postsecondary schooling alternatives differ depending on whether they are generated using observed tests scores or the underlying latent ability.

The rest of this paper is organized as follows: Section 2 describes the main features of the Chilean postsecondary education system. Section 3 describes our economic model and empirical strategy and presents a detailed analysis of our data. This section also defines the treatment effects of interest. Section 4 discusses the main empirical findings. Finally, section 5 concludes. 


\section{The Postsecondary Education System in Chile}

Chile's postsecondary education system has experienced rapid development over the last thirty years. The process began in 1981 with a reform that stimulated the entry of private institutions to the tertiary education system. As a result, the country transitioned from a postsecondary educational system dominated by public providers to one driven by competition between public and private institutions. The reform also increased the range of available postsecondary degrees. Before 1981, the vast majority of college graduates obtained five-year college degrees. After 1981, postsecondary institutions started offering two-, four-, and five-year degrees. The institutions offering two-year postsecondary degrees are known as Technical Institutes (TI or Centros de Formación Técnica), those offering four-year postsecondary degrees are know as Professional Institutes (PI or Institutos Profesionales), while universities continue offering five-year college degrees. ${ }^{4}$ Additionally, depending on the source of funding, universities can be further divided in three subcategories: Public, Private with access to public funding (PPF) and Private without access to public funding (Private).

More than thirty years after the original reform, Chile's postsecondary system is again under fire (OECD, 2009). Recently, the system has been criticized for a number of reasons. Arguably excessive tuition costs fueled an intense public debate, with many groups advocating for more tuition subsidies. ${ }^{5}$ At the same time, the quality of many higher education institutions has been questioned by students, public media, and even the government. Even though a large fraction of the students finance their education using private loans, the system is characterized by serious information problems. In fact, until recently, students did not have information on the employment prospects associated with different careers and postsecondary institutions when deciding where or whether to enroll. As a result of this, nothing prevented students (and their families) from making poorly informed financing decisions, which could lead to non-optimal outcomes from public and private perspectives. Our findings are consistent with this intuition. Many of these criticisms apply to the postsecondary schooling

\footnotetext{
${ }^{4}$ The number of postsecondary institutions in Chile rose from eight universities in 1980 to almost two hundred institutions in 2008 (61 universities, 45 PIs and 90 TIs). Also, the reform had an enormous impact in enrollment. Between 1984 and 2009, the enrollment in postsecondary institutions grew almost 363\% (from 189,151 to 876,243 students).

${ }^{5}$ Between 2005 and 2011, the average tuition had a real growth of $15 \%$, from US $\$ 3,292$ to US $\$ 3,785$.
} 
systems in other developed and developing countries. ${ }^{6}$

In Chile, access to postsecondary education is merit-based. Students who wish to attend college must take a national college admission test known as the PSU (Prueba de Selección Universitaria). Conditional on their PSU scores, high school graduates choose between enrolling in a postsecondary institution or entering directly into the labor market. Students are required to score a minimum of 450 points on the PSU to apply to PI (leading to fouryear degrees) and universities (five-year degrees). ${ }^{7}$ The only requirement for applying to TI (two-year degrees) is to have taken the PSU. Therefore, students with PSU scores higher than 450 points can choose among a wider variety of careers and postsecondary institutions. In addition to the general score guideline, each tertiary institution can choose to set an even more restrictive minimum score requirement. This is usually determined by the number of spots available.

This process produces positive sorting between academic performance, as measured by PSU scores, and enrollment by type of degree and institution. Figure 1 shows that most of the students with high PSU scores have higher unconditional probabilities of attending a university. The sorting profile is strongly influenced by students' socioeconomic background. As figure 2 documents, over $60 \%$ of the students whose gross family income is higher than 2,800 dollars per month (the average family income in 2008) enroll in private universities. Students with more educated mothers are also more likely to attend private and public universities (figure 3).

There are also significant differences in the labor market performance across postsecondary degrees and institutions (within a degree type). Figure 4 presents the average annual earnings received one and two years after graduation. The average earnings premium to graduating from PPF is the highest among the available degrees. Two- and four-year degrees present the lowest average premia. These results are confirmed in table 1, which presents the

\footnotetext{
${ }^{6}$ In april of 2012, The Economist published an article discussing some of these issues (http://www.economist.com/node/21552566).

${ }^{7}$ This motivates the regression discontinuity (RD) strategy used in Hastings, Neilson, and Zimmerman (2012), a recent study that came out to our attention after the first draft of this paper. The RD approach identifies the local return to education for those individuals above and below the cutoff. Our paper seeks to trace out the whole distribution of returns to education.
} 
OLS results from different Mincer-type regression specifications:

$$
\ln w_{i}=X_{i}^{\prime} \beta+T_{i}^{\prime} \delta+\sum_{s \in \mathcal{J}} \gamma_{s} D_{i, s}+u_{i}
$$

where $w_{i}$ represents monthly earnings, $X_{i}$ contains several demographic and socio-economic characteristics (gender, age, mother's education, family income), $T_{i}$ is the vector of test scores (language, math, among others), $D_{i, s}$ is a binary indicator taking a value of one if the individual reports $s$ as his postsecondary degree, and zero otherwise; $\mathcal{J}$ is the set of all available degrees, and $u_{i}$ is the error term. The information on postsecondary degrees (2008) and monthly earnings (2010) come from the Chilean postsecondary schooling system and the unemployment insurance system, respectively. We describe our data in more detail in section $3.5^{8}$

After accounting for individual characteristics, PPF and public universities exhibit the highest economic returns: $112.2 \%$ and $101.6 \%$, respectively (first column in table 1). These estimated returns decrease when we control for family background characteristics (columns 2 and 3) but they remain higher for PPF and Public universities than for TI and PI. When we add measures of academic performance (college admission tests and high school GPA), the estimated returns decrease further, but are still larger for PPF and public universities (columns 4 and 5).

However, to interpret these estimates as the causal effects of postsecondary degrees on earnings, we would need to make the strong assumption that, conditional on observed test scores $T_{i}$ and $X_{i}$, the set of dummy variables $\left\{D_{i, s}\right\}_{j \in \mathcal{J}}$ is independent from $u_{i}$. In other words, we would need to assume that selection is based exclusively on observed characteristics. Cameron and Heckman (2001) and Hansen, Heckman, and Mullen (2004) provide evidence that this is not a reasonable assumption. Individuals consider both observed and unobserved characteristics when sorting into schooling levels. On the other hand, labor market outcomes

\footnotetext{
${ }^{8}$ As described below, we analyze administrative academic records from the total population of graduates from higher institutions in Chile in 2008. This information contains standardized test scores (from PSU database), high school GPA and socio-economic variables for individuals who graduated from postsecondary institutions in 2008. Our sample includes individuals obtaining two-year TI degrees, four-year PI degrees and five-year university degrees (Public, PPF and Private). Additionally, we have information on individuals who took PSU in 2007 and decided not to enroll in postsecondary institutions, in 2008 or 2009. This sample defines the baseline category in table 1. We link the academic records to monthly earning information from 2010.
} 
are also determined by latent abilities (Heckman, Stixrud, and Urzua, 2006). Therefore, to the extent that observed test scores are not perfect proxies for latent ability, we can not provide a causal interpretation to the results in table 1. Furthermore, these results do not account for the direct tuition costs of education. As table 2 shows, these costs can be substantial. ${ }^{9}$ Consequently, we follow a different strategy in which we explicitly model schooling choices as a function of observed and unobserved characteristics, and compute the returns to postsecondary degrees net of tuition costs.

\section{The Economic Model and Empirical Strategy}

We posit a model of unordered schooling decisions. Conditional on unobserved ability, agents make schooling choices based on the comparison of the net expected utility associated with each postsecondary degree. ${ }^{10}$ This utility includes the potential economic benefits as well as monetary and psychic costs. The inclusion of psychic costs (or benefits) allows students to select alternatives that might not be optimal from a financial perspective.

We supplement the previous framework with a model of labor market outcomes (earnings) by type of degree. We assume that these outcomes are determined by the agent's observed and unobserved characteristics. Unobserved components, which we interpret as latent ability, generate a correlation between schooling choices and individual labor market outcomes. This delivers a model with essential heterogeneity, which allows for observationally equivalent individuals to experience different treatment effects even if they are making the same schooling decisions (Heckman, Urzua, and Vytlacil, 2006). We estimate a variety of treatment effects and analyze how they change with the level of unobserved ability.

\subsection{The Schooling Choice Model}

After graduating from high school, individuals decide between enrolling in one of the available higher education institutions, which leads to a specific degree, or entering the labor market.

\footnotetext{
${ }^{9}$ See Heckman, Lochner, and Todd (2008) for a precise discussion of the assumptions behind the Mincer model and their empirical justification.

${ }^{10}$ See Willis and Rosen (1979), Cameron and Heckman (1998, 2001), Carneiro, Hansen, and Heckman (2003) and Cameron and Taber (2004) for models with similar characteristics.
} 
Let $\mathcal{J}$ denote the set of all choices, and $j$ be a specific degree type, i.e., $j \in \mathcal{J} .^{11}$ Schooling choices depend on observed and unobserved characteristics. Let $\theta$ denote the unobserved individual endowment, which we interpret as latent ability. We assume $\theta$ is known to the agent.

We setup our choice model as in Cameron and Heckman (2001) and Heckman, Humphries, Urzua, and Veramendi (2011). Let $V_{i j}$ be the utility for student $i$ of choosing option $j$. This incorporates the economic returns as well as monetary and psychic costs for each alternative. We approximate $V_{i j}$ using the following linear function (for simplicity, we suppress the $i$ index):

$$
V_{j}=X_{j}^{V} \beta_{j}^{V}+\alpha_{j}^{V} \theta+\nu_{j}^{V}
$$

where $X_{j}$ presents the vector of exogenous characteristics, $\theta$ is unobserved ability and $\nu_{j}^{V}$ is the error term. We assume that conditional on individual characteristics, schooling choices are unordered. More precisely, agents choose the alternative that yields the highest expected utility:

$$
j^{*}=\arg \max _{j \in \mathcal{J}} E\left(V_{j} \mid \Omega\right)
$$

where $\Omega$ denotes the information set available to the individual. It includes observed and unobserved variables as well as the structure of the model. Later, we analyze the consequences of using unordered choices in the estimation of the returns to education in traditional structural schooling models (Heckman, Urzua, and Vytlacil, 2008).

Let $D_{j}$ denote an indicator function for option $j$ defined as:

$$
D_{j}= \begin{cases}1 & \text { if } j=\arg \max _{k \in \mathcal{J}} E\left(V_{k} \mid \Omega\right) \\ 0 & \text { otherwise }\end{cases}
$$

We utilize $D_{j}$ to define the treatment effects of postsecondary degrees.

Finally, we assume that agents graduate from high school at $t=0$, and that each postsecondary degree has a specific duration. We denote by $S_{j}$ the duration associated with postsecondary degree $j$. For students who decide not to continue on to postsecondary education, $S_{j}=0$. For the rest of the alternatives, $S_{j}>0$.

\footnotetext{
${ }^{11}$ We exclude from our model schooling decisions beyond postsecondary degrees and any possibility of dropping out after enrolling.
} 


\subsection{Labor Market Outcomes}

Let $y_{j}\left(S_{j}\right)$ denote annual initial earnings after obtaining a degree of type $j$. Likewise, let $g_{j}(t, t+1)$ denote the associated growth rate of earnings between $t$ and $t+1$. We can characterize the earnings profile for an agent graduating from degree $j$ as:

$$
\begin{array}{ll}
y_{j}(t)=0 & 0<t<S_{j} \\
y_{j}(t)=y_{j}\left(S_{j}\right) \times\left(1+g_{j}\left(S_{j}, S_{j}+1\right)\right) \times \ldots \times\left(1+g_{j}(t-1, t)\right) & S_{j} \leq t \leq T
\end{array}
$$

where $T$ denotes the retirement period, which we assume is common to all individuals. These expressions represent our model of counterfactual labor market outcomes and, as discussed below, they are the critical ingredients behind our estimated economic returns to postsecondary degrees. ${ }^{12}$

In the empirical implementation of the counterfactual outcome models, we assume that labor market outcomes are determined by observed characteristics as well as unobserved ability in the following manner: ${ }^{13}$

$$
\begin{array}{r}
y_{j}\left(S_{j}\right)=X_{j}^{y} \beta_{j}^{y}+\alpha_{j}^{y} \theta+\nu_{j}^{y} \\
g_{j}\left(S_{j}, S_{j}+1\right)=X_{j}^{g}\left(S_{j}\right) \beta_{j}^{g}+\alpha_{j}^{g} \theta+\nu_{j}^{g}
\end{array}
$$

where $\left(X_{j}^{y}, X_{j}^{g}\left(S_{j}\right)\right)$ represent vectors of exogenous controls, and $\left(\nu_{j}^{y}, \nu_{j}^{g}\right)$ are the error terms.

We use a conventional switching regression framework to define observed initial earnings $y\left(S_{j}\right)$ and growth rates $g\left(S_{j}, S_{j}+1\right)$ :

$$
\begin{aligned}
y\left(S_{j}\right) & =\sum_{j \in \mathcal{J}} D_{j} \times y_{j}\left(S_{j}\right) \\
g\left(S_{j}, S_{j}+1\right) & =\sum_{j \in \mathcal{J}} D_{j} \times g_{j}\left(S_{j}, S_{j}+1\right)
\end{aligned}
$$

\footnotetext{
${ }^{12}$ Given a specific degree type, individuals could enroll into different fields or disciplines (social sciences, biological sciences, computer science, etc). To the extent our schooling decision model captures the selection into types, and our labor market equations capture the heterogeneity between and within degree types, the selection into disciplines should not affect our identification strategy and the interpretation of the main results.

${ }^{13}$ This is similar to the empirical strategy in Willis and Rosen (1979), although we relax the assumption of normality.
} 
Note that $\theta$ affects labor market productivity as well as schooling choices. This unobserved factor is what drives the endogeneity of schooling decisions in our model.

\subsection{Measurement System for Unobserved Endowments}

The identification of the model of schooling choices and counterfactual labor market outcomes hinges on the identification of the distribution of unobserved ability $\theta, f_{\theta}(\cdot)$. We follow the strategy in Carneiro, Hansen, and Heckman (2003) and Hansen, Heckman, and Mullen (2004), and obtain this distribution using the information from a set of measurements (test scores). Let $\mathbf{T}$ be a vector of individual-level test scores (with at least three components) observed before the agent faces the postsecondary education decision problem. We assume a system of linear equations of the form:

$$
\mathbf{T}=\mathbf{X}^{T} \beta^{T}+\alpha^{T} \theta+\nu^{T}
$$

where $\mathbf{X}^{T}$ represents a vector of exogenous controls, and $\nu^{T}$ is the vector of residuals. Notice that the link between test scores and $\theta$ supports our interpretation of $\theta$ as latent ability.

Carneiro, Hansen, and Heckman (2003) show that in this context, the distribution of $\theta$ is non-parametrically identified up to a normalization of a single coefficient in $\alpha^{\mathbf{T}}$. We rely on their theory to develop our empirical analysis. For further details on the identifying assumptions of discrete-continuous factor models of endogenous decisions, labor market outcomes and test scores, see also Hansen, Heckman, and Mullen (2004).

\subsection{The returns to postsecondary degrees}

As mentioned earlier, the model allows for the identification of average and distributional treatment effects (Aakvik, Heckman, and Vytlacil, 2005). We focus on the impact of postsecondary degrees on labor market outcomes as defined by equations (4) and (5). Specifically, we use the models of initial earnings and growth rates to simulate the net economic benefits 
of each degree type $j \in \mathcal{J}$ using the following expression:

$$
P V_{j}=\sum_{t=S_{j}}^{T} \frac{\hat{y}_{j}(t)}{(1+r)^{t}}-\sum_{t=0}^{S_{j}-1} \frac{C_{j}(t)}{(1+r)^{t}}
$$

where $\hat{y}_{j}(t)$ represents the predicted earnings in period $t$ for degree type $j$ (see expression (3)) and $C_{j}(t)$ denotes the respective annual tuition costs.

It is worth mentioning that $P V_{j}$ is not necessarily an estimate of $V_{j}$. In our model, an individual may not choose the alternative that yields the highest economic returns. Allowing for $V_{j}$ to include psychic costs rationalizes a model in which individuals make optimal choices based on expected net utility, but may not make the best financial decision (Cameron and Heckman, 2001; Cunha, Heckman, and Navarro, 2005). Differences between $P V_{j}$ and $V_{j}$ could also be due to individual having a distorted information set available at the time of the decision and/or forecast errors. However, Cunha, Heckman, and Navarro (2006) find that forecast errors explain only a small portion of the gap between $V_{j}$ and $P V_{j}$ in the United States. $^{14}$

We use this methodology to analyze two alternative definitions of the net economic returns to postsecondary degrees. First, we compare each option against the alternative of not continuing onto postsecondary studies. This is the traditional definition of the individual's return to postsecondary education. Individuals choosing not to continue to postsecondary education have a stream of earnings defined by $y_{0}(t)$ and $g_{0}(t, t+1)$, while $C_{0}(t)=0$ for all $t$. The present discounted value of the no postsecondary schooling choice is given by:

$$
P V_{0}=\sum_{t=0}^{T} \frac{\hat{y}_{0}(t)}{(1+r)^{t}}
$$

where $r$ denotes the relevant interest rate.

Let $\Delta_{j}^{0}$ represent the purely financial benefit or loss (that is, excluding psychic costs or benefits) to choosing option $j$ instead of no postsecondary education. $\Delta_{j}^{0}$ is defined at the individual-level as:

$$
\Delta_{j}^{0}=P V_{j}-P V_{0}
$$

\footnotetext{
${ }^{14}$ In this paper we do not decompose the gap between $V_{j}$ and $P V_{j}$ into uncertainty and psychic costs.
} 
However, in analyzing the costs and benefits of a particular choice $j$, the agent compares its associated benefits and costs against those from all alternatives in $\mathcal{J}$, not just to the no postsecondary schooling option. In particular, if for some $j, k$ both in $\mathcal{J}, \Delta_{j}^{0}>0$ and $\Delta_{k}^{0}>0$, then the relevant comparison is between $P V_{j}$ and $P V_{k}$. Following this intuition, our second definition for the return to postsecondary degrees is based on the comparison of the benefits and costs associated with the first-best versus second-best alternatives. Specifically, let $j^{*}$ and $k^{*}$ be the first and second best options, respectively. That is:

$$
\begin{aligned}
j^{*} & =\operatorname{argmax}_{j \in \mathcal{J}}\left\{V_{j}\right\} \\
k^{*} & =\operatorname{argmax}_{k \in \mathcal{J} \mid-j^{*}}\left\{V_{k}\right\},
\end{aligned}
$$

and let $P V_{j^{*}}$ and $P V_{k^{*}}$ be the corresponding net economic benefits. We define the following individual-level treatment parameter:

$$
\Delta_{j^{*}}^{k^{*}}=P V_{j^{*}}-P V_{k^{*}}
$$

which identifies the economic benefits of graduating from the first-best option, $j^{*}$, versus the second-best alternative $k^{*}$ With $\Delta_{j}^{0}$ and $\Delta_{j}^{k}$, we can estimate the average treatment on the treated effect as follows:

$$
\begin{aligned}
T T_{j}^{0} & \equiv \iint \Delta_{j}^{0}\left[\left(X_{j}^{y}(t), X_{j}^{g}(t)\right)=x, \theta=z\right] d F_{\mathbf{X}, \theta \mid D_{j}=1}(x, z) \\
T T_{j}^{k} & \equiv \iint\left(\sum_{k \in \mathcal{J} \mid-j} \Delta_{j}^{k}\left[\left(X_{j}^{y}(t), X_{j}^{g}(t)\right)=x, \theta=z\right] \times \operatorname{Pr}\left[D_{k \in \mathcal{J} \mid-j}=1 \mid D_{j}=1\right]\right) d F_{\mathbf{X}, \theta \mid D_{j}=1, D_{k \in \mathcal{J} \mid-j}=1}(x, z)
\end{aligned}
$$

where the indicator function $D_{k^{*} \in \mathcal{J} \mid-j^{*}}$ takes a value of 1 if $k^{*}$ is the optimal choice in $\mathcal{J}$ when $j^{*}$ is excluded, and 0 otherwise.

Equation (11) is the usual expression for estimating treatment on the treated effects for a particular schooling level. ${ }^{15} T T_{j}^{0}$ assumes that the relevant counterfactual for estimating average treatment effects is the alternative of not graduating from any postsecondary alternative. Equation (12) is a modification of the conventional definition. Given that we are

\footnotetext{
${ }^{15}$ See, e.g., Aakvik, Heckman, and Vytlacil (2005) and Heckman, Humphries, Urzua, and Veramendi (2011).
} 
considering different choices within a particular set of options, our average treatment on the treated effect should be averaged over the probability of $k$ being the second-best choice given that $D_{j}=1$. In this way, $T T_{j}^{k}$ offers a different and potentially more realistic perspective to the returns to education.

\subsection{Empirical Implementation}

Data. Our data include administrative records on individual-level postsecondary degrees, test scores and earnings. The information on postsecondary degrees comes from administrative registers from the Chilean Ministry of Education. Table 3 presents the list of institutions from which we observe the universe of postsecondary degrees granted in 2008. We have information from 69 TIs, 36 PIs, 16 Public universities and 30 Private universities. We gather information on PSU test scores from the postsecondary admission test system for the period 2001-2007 (PSU). ${ }^{16}$ The PSU evaluates students' proficiency in the subjects of math, language, geography and science. This data also contains a rich set of individual-level information, including each student's socio-economic characteristics and average GPA during high school.

Information on labor market outcomes comes from the Ministry of Labor's Unemployment Insurance System (UIS). The UIS records monthly earnings for all workers with formal contracts in the country since November 2002. By 2010, the data contains information from more than 7 million workers. ${ }^{17,18}$

In order to estimate the economic benefits to not graduating from a postsecondary institution, we build a comparison group (control group) using individuals entering the labor market right after finishing high school in 2007. We construct this group by gathering information from administrative records on those enrolled in higher education institutions and the college admission system. Specifically, we identify individuals that took PSU in 2007, but

\footnotetext{
${ }^{16}$ Between 2001 and 2003, PAA (Prueba de Aptitud Academica) was the national college admission test. The data description applies for both PAA and PSU.

${ }^{17}$ According to the Chilean Bureau of Statistics, average quarterly employment in the country was 7,1 million in 2010 .

${ }^{18}$ The total number of individuals obtained a postsecondary degree in 2008 is 50,0041. After deleting observations with missing information on exogeneous controls and monthly earnings, we end up with 31,045 observations. On the other hand, 51,031 individuals participated in the college admission process in 2007 (took PSU) but did not enroll in any postsecondary institution in 2008 or 2009. After deleting observations with missing information on exogeneous controls and monthly earnings, we end up with 26,114 observations.
} 
did not appear enrolled in 2008 or 2009. In this way, we compare the labor market outcomes of those graduating from postsecondary institutions in 2008 to individuals entering the labor market at the same time, without any postsecondary schooling. ${ }^{19}$

We use the math, language and geography PSU scores to estimate the measurement system described in equation (6). We include average high school GPA (obtained from PSU records) as part of the measurement system. Because 2008 graduates might come from careers with different durations, we obtain their PSU test scores from several different years. We look for PSU scores in administrative records over the period 2001 to 2005 . Because the PSU scores are not comparable over time, we use year-specific percentiles as our measures of academic performance. The list of covariates in the measurement system includes age, gender, and mother's education, all of which are obtained from the PSU administrative records.

In our multinomial choice estimations, we include as exogenous controls gender, age (2008), mother's education and family income (from PSU records). We also incorporate average regional tuition costs for each potential postsecondary degree. This information contributes to the identification of our schooling choice model (Card, 1999; Heckman and Navarro, 2007).

For labor market outcomes, we use the monthly earnings between August 2008 and July 2009 to construct average monthly earnings in 2008. This is our dependent variable in equation (4). ${ }^{20}$ Analogously, we use earnings between August 2010 and July 2011 to construct the average monthly earnings for 2010 . We compute the growth rate of earnings $g_{j}\left(S_{j}, S_{j}+1\right)$ using the individual-level information for the years 2008 and 2010. In equations (4) and (5) we include age and gender covariates.

Tables 4 and 5 present the explanatory variables included in the educational multinomial

\footnotetext{
${ }^{19}$ Each agent in our model selects the schooling level that maximizes his expected utility. We assume that in forming these expectations he uses all available information. In this way, recent high school graduates should consider the labor market outcomes of recent college graduates to decide whether or not to continue their education. This logic justifies our control group in the context of our schooling choice setup. We recognize that the cohort of recent high school graduates might underestimate the counterfactual labor market outcomes for college graduates, and overestimate the returns to postsecondary education. But since we find a large fraction of individuals with negative net returns to postsecondary degrees, our main conclusion is robust to the definition of the control group.

${ }^{20} \mathrm{We}$ assume zero earnings for months of unemployment or inactivity. We then compute average monthly earnings using 12 observations per individual. For those individuals with average monthly earnings below the legal minimum wage divided by 12 , we assume zero earnings. We do this to make sure we are considering earnings coming from at least one month of formal full time employment during the year. The minimum wage was set to US\$ 318 between July 2008 and June 2009 and US\$ 344 per month between July 2010 and June 2011.
} 
choice model, the test score measurement system and the labor market outcome equations. Summary statistics of the variables are presented in table 6 .

Estimation. We assume that the distribution of $\theta, f(\theta)$, can be approximated as a mixture of two normal distributions with means $\left(\mu_{1}, \mu_{2}\right)$ (with the overall mean of $\theta$ restricted to zero), probabilities $\left(p_{1}, p_{2}\right)$, and variances $\left(\Sigma_{1}, \Sigma_{2}\right)$ :

$$
\theta \sim p_{1} \Phi\left(\mu_{1}, \Sigma_{1}\right)+p_{2} \Phi\left(\mu_{2}, \Sigma_{2}\right)
$$

with $p_{1}+p_{2}=1$. Therefore, we use flexible distributional assumptions to estimate the distribution of unobserved ability.

The likelihood function of the model is given by the following expression:

$$
\begin{aligned}
\mathcal{L} & =\prod_{i} f\left(\mathbf{Y}_{i}, \mathbf{D}_{i}, \mathbf{T}_{i} \mid \mathbf{X}_{i}\right) \\
& =\prod_{i} \int f\left(\mathbf{Y}_{i} \mid \mathbf{D}_{i}, \mathbf{X}_{i}, \theta\right) f\left(\mathbf{D}_{i}, \mathbf{T}_{i} \mid \mathbf{X}_{i}, \kappa\right) f_{\theta}(\kappa) d \theta
\end{aligned}
$$

where $\mathbf{Y}_{i}$ is a vector containing individual $i$ 's labor market outcomes $\left(\mathbf{Y}_{i}=\left[y_{j}\left(S_{j}\right), g_{j}\left(S_{j}, S_{j}+\right.\right.\right.$ 1)]), $\mathbf{X}_{i}$ contains his observed exogenous characteristics $\left(\mathbf{X}_{i}=\left[X_{j}^{V}(t), X_{j}^{y}(t), X_{j}^{g}(t)\right]\right), \mathbf{D}_{i}$ denotes observed schooling choice and $\mathbf{T}_{i}$ contains test scores. We assume that the idiosyncratic errors in equation (1) are distributed according to independent standardized normal distributions. We follow Hansen, Heckman, and Mullen (2004) and assume that $\mathbf{X}$ and $\theta$ are independent. The disturbances in equations (4), (5) and (6) are also assumed to be drawn from independent normal distributions with mean zero. The associated variances are estimated by our empirical strategy. Given $\theta_{i}$ and $\mathbf{X}_{i}$, the distribution of counterfactuals is identified and all errors in the model are independent from each other.

The empirical implementation follows a Bayesian Markov Chain Monte Carlo (MCMC) method. ${ }^{21}$ The model's estimates are used to simulate 100,000 draws. For each draw, we predict schooling choices and labor market outcomes for each counterfactual.

\footnotetext{
${ }^{21}$ For more details see Carneiro, Hansen, and Heckman (2003) and Hansen, Heckman, and Mullen (2004).
} 


\section{The Returns to Postsecondary Degrees}

We use the model's estimated parameters to generate the returns to postsecondary degrees in Chile. Figure 5 presents the estimated distribution of unobserved ability. It confirms previous findings documenting that unobserved ability might not be normally distributed (Heckman, Stixrud, and Urzua, 2006).

Table 7 shows the estimates of our multinomial probit model. Estimated coefficients suggest that students coming from a rich home environment (high-income families and educated mothers) have a higher probability of obtaining a postsecondary degree, particularly from Public and Private universities (five-year degrees).

Our results also indicate that an increase in annual tuition reduces the probability of graduating from Public and PPF universities. In contrast, it increases the likelihood of choosing TI and PI. Initially, these results might seem counterintuitive. However, one possible explanation is that tuition costs are interpreted as proxies of quality. In other words, these costs could contribute to information asymmetries in the postsecondary schooling market if there is lack of reputational mechanisms identifying institutions that do not provide good quality services. It implies that individuals who are more likely to choose PI and TI, perceive a positive relation between provided quality and tuition costs.

Conditional on observed individual characteristics and the costs of postsecondary education, we obtain a positive relationship between unobserved abilities and the probability of graduating from PI and university (including public and private institutions). In contrast, estimates show a negative relationship between our measure of unobserved individual ability and the probability of obtaining a two-year postsecondary degree from a TI. Our results also indicate heterogeneity among the individuals choosing universities. In particular, we find that high-ability individuals are more likely to choose PPF compared to public, private and PI institutions.

Table 8 presents estimates from the test score equations. The coefficients on age and gender are statistically significant and show the expected signs. In particular, males perform better in math and geography, while females obtain higher scores in language and have better grades during high school (measured by GPA). Also, the coefficients associated with unobserved ability all have positive signs and they all are statistically significant at the $1 \%$ 
level.

Estimates of the equations for labor market outcomes are presented in table 9. Coefficients from initial earning equations (columns 1 to 6 ) show that unobserved endowments are positively correlated with initial earnings. The male and age coefficients have positive signs and are statistically significant at $1 \%$ level. The earnings growth estimates are presented in columns 7 to 12 . Here, the age coefficients have negative signs, suggesting, on average, earnings profiles are concave (except for graduates from two-year degrees - TI). Our estimates suggest that higher ability individuals would have a flatter earnings profile if they chose to graduate from private universities or not to continue on to any postsecondary studies.

In order to evaluate the goodness of fit our model, we compare the distribution of choices between the observed data and the model samples. We do this by simulating data from our estimated parameters. As figure 6 shows the simulated data closely resembles the distribution of choices. Additionally, we compare average monthly earnings and the associated growth rates between the observed data and the model simulated sample. Figures 7 and 8 show that our model mimics the observed patterns in the data despite slightly overestimating growth rates of earnings. ${ }^{22}$

Figure 9 presents the variance decomposition of test scores as a function of observables (gender, age, mother's education and family income), the individual's latent ability, and the error term. For language, math and geography; unobserved ability explains a significant fraction of the overall variances (between $42.2 \%$ and $50.1 \%$ depending on the specific test). The observed regressors and the error terms explain approximately $25 \%$ of the variance. In the case of high school GPA, a significant percentage of the variance is explained by the error term $(58 \%), 32.9 \%$ is explained by the factor, and only a small fraction (9\%) is attributed to observable elements.

It is interesting to compare the simulated sorting profile on the different degrees implied by the latent ability $(\theta)$ and the error-contaminated measurement of $\theta$ (PSU scores). This exercise shed lights on the importance of distinguishing between the two. Figures 10 and 11 present these results. For high-ability individuals both the PSU and $\theta$ produce similar sorting. The highest ability individuals are more likely to choose PPF, Public and Private universities

\footnotetext{
${ }^{22}$ Tables A1-A3 in the appendix compare means, variances and distributions for test scores and labor market outcomes between the observed data and the model simulated sample.
} 
(in that order). Surprisingly, for lower ability individuals $\theta$ and PSU scores produce different sortings. According to the estimated PSU distribution, low-scoring students tend to choose to not graduate from postsecondary education or to graduate from two-year degrees. However, if we use the estimated $\theta$ distribution, TI and PI graduates tend to have lower latent ability. This suggests that estimates based only on observable measurements -such as PSU scoreslead to a different sorting structure than the actual latent factor. Thus, OLS estimates using PSU as proxies for latent ability, are potentially biased.

Following equation (3), we estimate the average stream of annual earnings $\hat{y}_{j}(t)$ for each schooling choice $j$. We compute yearly earnings, for this age range. Figure 12 displays the conditional earnings profiles, starting at age 18 and ending at 35 . There is significant heterogeneity across alternatives. Moreover, the estimated earnings profiles are not parallel across the different alternatives. For example, on average, the profile of people with degrees from private universities has higher initial earnings than one for PI graduates, but this gap reduces with age.

Treatment Effects. We use the results from our model and administrative data on tuition costs to compute the individual-level net present value of earnings $P V_{j}$ for each degree type $j$ as well as the treatment effects defined in equations (8) and (7). We assume a constant discount rate of 0.04 .

Table 10 presents our estimates for $T T_{j}^{k}$ (first best versus second best options) and $T T_{j}^{0}$ (first best option versus not pursuing a postsecondary degree). The results confirm that, on average, obtaining a postsecondary degree would lead to net positive economic returns. For $T T_{j}^{0}$, five-year postsecondary degrees (universities) have the highest returns among all alternatives, particularly when obtained from PPF universities. Nevertheless, our results also document the existence of substantial heterogeneity in the returns. Specifically, we find that the portion of individuals receiving negative returns to their postsecondary degree ranges from $35 \%$ to $42 \%$ (third column in table 10). ${ }^{23}$ Even if we disregard individuals at the

${ }^{23}$ We calculate rates of return as:

$$
\begin{aligned}
& r_{j}^{0}=\left(P V_{j}-P V_{0}\right) / P V_{0} \\
& r_{j}^{k}=\left(P V_{j}-P V_{k}\right) / P V_{k}
\end{aligned}
$$

where $P V_{0}$ and $P V_{k}$ are defined in the main text. Treatment effects are calculated according to equations (11) and $(12)$. 
margin (fourth column), we still find a large number of individuals with negative returns. These individuals would have been financially better-off not continuing schooling beyond high school. This might suggest the existence of psychic benefits to postsecondary education. This is in line with the findings of Carneiro, Hansen, and Heckman (2003); Cunha, Heckman, and Navarro (2005, 2006); Heckman, Lochner, and Todd (2006). Alternatively, this may be the result of a lack of information at the time the schooling decisions are made. Although we do not decompose the treatment effects variance into the these two components, Carneiro, Hansen, and Heckman (2003) find that uncertainty coming from forecast errors has little effect on schooling choices. Furthermore, we find that individuals with a higher stock of unobserved abilities also have higher values of $T T_{j}^{k}$ (figure 13).

Next, we analyze the results for $T T_{j}^{k}$. Estimated returns fall drastically and the portion of individuals realizing negative economic returns rises considerably. It is interesting to note that private universities have the highest economic returns. Moreover, as the differences between the first- and second-best option shrink, $T T_{j}^{k}$ becomes now lower for PPF than for private universities.

To understand this result, we look at the distribution of first and second best choices. Table 11 presents these results. The second best choice distribution follows the rank-order of economic benefits closely. For individuals choosing TI, the most popular second choice is not enrolling in a tertiary institution. The distribution of second-best choices for individuals choosing private universities is roughly uniform across the other alternatives. PPF institutions, on the other hand, the vast majority of second best choices are concentrated in public universities. ${ }^{24}$

$T T_{j}^{k}$ also varies with our measure of latent ability $\theta$. For example, for two-year degrees (TIs) $T T_{j}^{k}$ is decreasing in $\theta$ (figure 14). This implies that high-skilled individuals graduating from a TI would have been better-off financially selecting their second best alternative. For Public universities there is a similar phenomenon: as $\theta$ rises, $T T_{j}^{k}$ decreases because the second best alternative starts to increase in economic value. For the other postsecondary degrees (Private, PI and PPF) higher $\theta$ produces greater economic benefit according to our measure $T T_{j}^{k}$.

\footnotetext{
${ }^{24}$ In table A.4 we show estimated $T T_{j}^{k}$ by second choices.
} 
Overall, our findings suggest that a substantial fraction of individuals make schooling decisions that lead to negative net economic returns. As explained above, we cannot determine if these "mistakes" are due to a lack of information or to individual preferences (psychic benefits). We can, however, show that our estimated treatment effects are directly affected by latent ability. This confirms the important role of unobserved heterogeneity in determining individual's expectations and/or psychic costs/benefits.

Policy experiment: The effect of tuition subsidies. We utilize our model to investigate the effects of a reduction in tuition costs on schooling decisions. We follow the analysis presented in Carneiro, Hansen, and Heckman (2003) and simulate the impact of a uniform reduction in tuition for all institution types. Then, we extend the analysis and simulate a relative reduction in costs for each postsecondary institution type. This enables us to trace out the behavioral responses to heterogeneous changes in tuition costs across institutions.

Table 12 shows the distribution of school choices after a $10 \%$ reduction in tuition costs for all institution types. ${ }^{25}$ Contrary to what we expected, total enrollment in postsecondary institutions is essentially unaffected by the change (a reduction of only 0.94\%). However, disguised by the stable overall enrollment, we observe significant changes in the composition of enrollment across degrees and institutions.

Specifically, we observe a reduction in PI enrollment (17,34\% - i.e, from 9,158 to 7,570$)$ and Private enrollment (6,9\% - i.e, from 17,940 to 16,700), and an increase in enrollment for the other institution types. TI, Public and PPF experience an increase in enrollment of $2.25 \%$ (from 5,537 to 5,662 ), $8.83 \%$ (from 13,408 to 14,590 ) and $12.62 \%$ (from 8,028 to $9,041)$, respectively.

These findings confirm the importance of allowing for heterogeneity across types of higher education institutions. They also suggest that changes in tuition costs produce no significant effects on overall enrollment, after controlling for family background characteristics and ability. This suggests that short-term credit constraints might not play a major role in the Chilean postsecondary education system (at least in terms of the probability of obtaining a degree).

\footnotetext{
${ }^{25}$ We allow the direct costs differ across different types of institutions, so the $10 \%$ reduction modifies the relative costs. Table 2 presents average values per institution.
} 


\section{Conclusions}

In this paper we estimate heterogeneous returns to different types of postsecondary institutions in Chile. We account for observed and unobserved selection across the available alternatives. Our identification strategy is based on the presence of an unobserved endowment (ability), which generates the correlation between schooling choices and future labor market outcomes. Our model is capable of producing a variety of treatment effects. Our results demonstrate an important sorting component based on unobserved ability, confirming the advantages of our approach over more traditional empirical strategies.

Compared to the alternative of graduating from high school and not pursuing a postsecondary degree, on average, all postsecondary degrees have positive economic returns. However, there is significant heterogeneity in our estimates. We document that a large proportion of students are willing to accept negative monetary returns to postsecondary degrees. Moreover, we exploit the structure of our schooling choice model and compute a treatment effect that compares the economic returns to the first-best versus the second-best alternative. In this case we find an even larger fraction of individuals experiencing negative returns. These findings might be due to either the presence of psychic benefits (Cunha, Heckman, and Navarro, 2005, 2006) or informational asymmetries.

Finally, we estimate that a reduction in tuition costs produces non-trivial changes in the composition of postsecondary graduates, but does not affect overall enrollment levels. This

highlights the importance of allowing for heterogeneous returns to postsecondary degrees. Furthermore, consistent with the results in Cameron and Heckman (2001) and Carneiro and Heckman (2002), this suggests that financial constraints are not playing a major role in the Chilean postsecondary education system. 


\section{References}

Aakvik, A., J. J. Heckman, And E. J. Vytlacil (2005): "Estimating Treatment Effects for Discrete Outcomes When Responses to Treatment Vary: An Application to Norwegian Vocational Rehabilitation Programs," Journal of Econometrics, 125(1-2), 15-51.

Arellano, S., And M. Braun (1999): "Rentabilidad de la Educación Formal en Chile," Cuadernos de Economía, (107), 685-724.

Bassi, M., M. Busso, S. Urzua, And J. Vargas (eds.) (2012): Disconnected: Skills, education and employment in Latin America. Inter-American Development Bank, Philadelphia, PA.

Behrman, J., N. Birdsall, and M. Szekely (2007): "Economic Policy and Wage Differentials in Latin America," Economic Development and Cultural Change, 56(1).

Cameron, S. V., And J. J. Heckman (1998): "Life Cycle Schooling and Dynamic Selection Bias: Models and Evidence for Five Cohorts of American Males," Journal of Political Economy, 106(2), 262-333.

- (2001): "The Dynamics of Educational Attainment for Black, Hispanic, and White Males," Journal of Political Economy, 109(3), 455-99.

Cameron, S. V., And C. TABer (2004): "Estimation of Educational Borrowing Constraints Using Returns to Schooling," Journal of Political Economy, 112(1), 132-182.

CARD, D. (1993): "Using Geographic Variation in College Proximity to Estimate the Return to Schooling," Discussion Paper 4483, National Bureau of Economic Research.

— (1999): "The Causal Effect of Education on Earnings," in Handbook of Labor Economics, ed. by O. Ashenfelter, and D. Card, vol. 5, pp. 1801-1863. North-Holland, New York.

(2001): "Estimating the Return to Schooling: Progress on Some Persistent Econometric Problems," Econometrica, 69(5), 1127-1160. 
Carneiro, P., K. Hansen, and J. J. Heckman (2003): "Estimating Distributions of Treatment Effects with an Application to the Returns to Schooling and Measurement of the Effects of Uncertainty on College Choice," International Economic Review, 44(2), $361-422$.

Carneiro, P., And J. J. Heckman (2002): "The Evidence on Credit Constraints in PostSecondary Schooling," Economic Journal, 112(482), 705-734.

Carneiro, P., J. J. Heckman, and E. J. Vytlacil (2011): "Estimating Marginal and Average Returns to Education," American Economic Review, 101(773), 2754-2781.

Contreras, D., E. Melo, And S. OJeda (2005): "Estimando el Retorno a la Educación o a los no Observables?: Evidencia de Datos de Danel," Estudios de Economía, 32(2), 187-199.

Cunha, F., J. J. Heckman, and S. Navarro (2005): "Separating Uncertainty from Heterogeneity in Life Cycle Earnings, The 2004 Hicks Lecture," Oxford Economic Papers, $57(2), 191-261$.

(2006): "Counterfactual Analysis of Inequality and Social Mobility," in Mobility and Inequality: Frontiers of Research in Sociology and Economics, ed. by S. L. Morgan, D. B. Grusky, and G. S. Fields, chap. 4, pp. 290-348. Stanford University Press, Stanford, CA.

Hansen, K. T., J. J. Heckman, and K. J. Mullen (2004): "The Effect of Schooling and Ability on Achievement Test Scores," Journal of Econometrics, 121(1-2), 39-98.

Hastings, J., C. Neilson, And S. Zimmerman (2012): "Determinants of causal returns to postsecondary education in Chile: What's luck got to do with it?," unpublished manuscript.

Heckman, J. J., J. Humphries, S. Urzua, and G. Veramendi (2011): "The Effects of Schooling on Labor Market, Health, and Social Outcomes," Working Papers 2011-002, Human Capital and Economic Opportunity Working Group. 
Heckman, J. J., L. J. Lochner, And P. E. Todd (2006): "Earnings Equations and Rates of Return: The Mincer Equation and Beyond," in Handbook of the Economics of Education, ed. by E. A. Hanushek, and F. Welch, chap. 7, pp. 307-458. Elsevier, Amsterdam.

(2008): "Earnings Functions and Rates of Return," Journal of Human Capital, 2(1), $1-31$.

Heckman, J. J., And S. Navarro (2007): "Dynamic Discrete Choice and Dynamic Treatment Effects," Journal of Econometrics, 136(2), 341-396.

Heckman, J. J., J. Stixrud, And S. Urzua (2006): "The Effects of Cognitive and Noncognitive Abilities on Labor Market Outcomes and Social Behavior," Journal of Labor Economics, 24(3), 411-482.

Heckman, J. J., S. URzua, and E. J. Vytlacil (2006): "Understanding Instrumental Variables in Models with Essential Heterogeneity," Review of Economics and Statistics, $88(3), 389-432$.

(2008): "Instrumental Variables in Models with Multiple Outcomes: The General Unordered Case," Les Annales d'Economie et de Statistique, Forthcoming.

Kane, T. J. (1996): "College Cost, Borrowing Constraints and the Timing of College Entry," Eastern Economic Journal, 22(2), 181-194.

- (1999): The Price of Admission: Rethinking How Americans Pay for College. Brookings Institution, Washington, D.C.

Kane, T. J., And C. E. Rouse (1995): "Labor-Market Returns to Two- and Four-Year College," American Economic Review, 85(3), 600-614.

Keane, M. P., And K. I. Wolpin (1997): “The Career Decisions of Young Men,” Journal of Political Economy, 105(3), 473-522.

Lustig, N., And L. Lopez-Calva (eds.) (2010): Declining inequality in Latin America: A decade of progress? Brookings Institution Press, Baltimore, MD. 
Manacorda, M., C. Sanchez-Parama, and N. Schady (2010): "Change in the returns to education in Latin America: The role of demand and supply of skills," Industrial and Labor Relations, 63(2).

Meller, P. (2010): Carreras Universitarias, Rentabilidad, Selectividad y Discriminación. Editorial Uqbar.

Meller, P., AND D. RAppoport (2006): "Son siempre las Universidades la mejor opción para un Título Profesional? Evidencia chilena," Banco Central de Chile, 2(389), 311-332.

OECD (2009): "The Postsecondary Education in Chile: A Review of National Policies in Education," Technical Report.

RAU, T. (2013): "Modeling structural equations with endogenous regressors and heterogeneity through derivative constraints," Quantitative Econometrics, Forthcoming.

SAPELli, C. (2003): "Ecuaciones de Mincer y Las Tasas de Retorno a la Educación en Chile: 1990-1998," Pontificia Universidad Católica, Instituto de Economía, Working Paper 254.

Taber, C. R. (2001): "The Rising College Premium in the Eighties: Return to College or Return to Unobserved Ability?," Review of Economic Studies, 68(3), 665-691.

UrzuA, S. (2008): "Racial Labor Market Gaps: The Role of Abilities and Schooling Choices," Journal of Human Resources, 43(4), 919-971.

Willis, R. J., AND S. Rosen (1979): "Education and Self-Selection," Journal of Political Economy, 87(5, Part 2), S7-S36. 
Table 1: OLS estimates from Mincer-type regression

\begin{tabular}{lccccc}
\hline \hline \multicolumn{1}{c}{ Variable } & $(1)$ & $(2)$ & $(3)$ & $(4)$ & $(5)$ \\
\hline Two-year degree (TI) & $0.453^{* * *}$ & $0.446^{* * *}$ & $0.439^{* * *}$ & $0.436^{* * *}$ & $0.380^{* * *}$ \\
& $(0.022)$ & $(0.022)$ & $(0.022)$ & $(0.022)$ & $(0.022)$ \\
Four-year degree (PI) & $0.678^{* * *}$ & $0.663^{* * *}$ & $0.648^{* * *}$ & $0.616^{* * *}$ & $0.564^{* * *}$ \\
& $(0.019)$ & $(0.019)$ & $(0.019)$ & $(0.019)$ & $(0.019)$ \\
Five-year degree (Public) & $1.016^{* * *}$ & $0.993^{* * *}$ & $0.976^{* * *}$ & $0.777^{* * *}$ & $0.687^{* * *}$ \\
& $(0.019)$ & $(0.019)$ & $(0.019)$ & $(0.021)$ & $(0.021)$ \\
Five-year degree (PPF) & $1.122^{* * *}$ & $1.088^{* * *}$ & $1.030^{* * *}$ & $0.790^{* * *}$ & $0.705^{* * *}$ \\
& $(0.021)$ & $(0.022)$ & $(0.022)$ & $(0.024)$ & $(0.024)$ \\
Five-year degree (Private) & $0.946^{* * *}$ & $0.911^{* * *}$ & $0.837^{* * *}$ & $0.753^{* * *}$ & $0.702^{* * *}$ \\
& $(0.018)$ & $(0.019)$ & $(0.019)$ & $(0.019)$ & $(0.019)$ \\
\hline Male & Yes & Yes & Yes & Yes & Yes \\
Age & Yes & Yes & Yes & Yes & Yes \\
Mother's Education & No & Yes & Yes & Yes & Yes \\
Family Income & No & No & Yes & Yes & Yes \\
PSU & No & No & No & Yes & Yes \\
GPA & No & No & No & No & Yes \\
Observations & 28,447 & 28,447 & 28,447 & 28,447 & 28,447 \\
\hline
\end{tabular}

Notes: The dependent variable is (log) average monthly earnings in 2010. Postsecondary degrees are defined as: two-year degrees obtained in Technical Institutes (TI), four-year degrees obtained in Professional Institutes (PI) and five-year degrees obtained in Public Universities (Public), Private universities receiving public funding (PPF) and Private universities without public funding (Private). Standard errors in parentheses. ${ }^{* * *} \mathrm{p}<0.01 .{ }^{* *} \mathrm{p}<0.05 .{ }^{*} \mathrm{p}<0.1$. 
Table 2: Annual Tuition by Type of Institution and Region (US per year, 2007)

\begin{tabular}{cccccc}
\hline \hline Region & TI & PI & Public & PPF & Private \\
\hline I & 1,770 & 1,906 & 2,646 & 2,341 & 2,341 \\
II & 1,914 & 1,901 & 3,058 & 1,642 & 2,607 \\
III & 1,537 & 1,763 & 2,718 & 2,262 & 2,262 \\
IV & 1,505 & 1,775 & 2,991 & 4,018 & 2,955 \\
V & 1,559 & 1,927 & 2,152 & 3,353 & 3,183 \\
VI & 1,867 & 1,945 & 2,177 & 2,318 & 2,318 \\
VII & 1,536 & 1,696 & 3,895 & 2,492 & 2,492 \\
VIII & 1,606 & 1,713 & 2,826 & 2,952 & 3,222 \\
IX & 1,537 & 1,971 & 2,813 & 3,401 & 2,941 \\
X & 1,548 & 1,658 & 2,133 & 3,939 & 2,944 \\
XI & 1,927 & 1,789 & 2,021 & 2,021 & 2,021 \\
XII & 1,747 & 1,728 & 3,067 & 2,211 & 2,211 \\
RM & 1,538 & 1,969 & 3,322 & 5,473 & 3,662 \\
\hline National Average & $\mathbf{1 , 6 6 1}$ & $\mathbf{1 , 8 2 6}$ & $\mathbf{2 , 7 5 5}$ & $\mathbf{2 , 9 5 6}$ & $\mathbf{2 , 7 0 5}$ \\
\hline
\end{tabular}

Source: Chilean Ministry of Education. Notes: (a) We only consider tuition costs for undergraduate careers. (b) Categories of degrees by institution types are define as: two-year degrees obtained in Technical Institutes (TI), four-year degrees obtained in Professional Institutes (PI) and five-year degrees obtained in Public Universities (Public), Private universities receiving public funding (PPF) and Private universities without public funding (Private). 


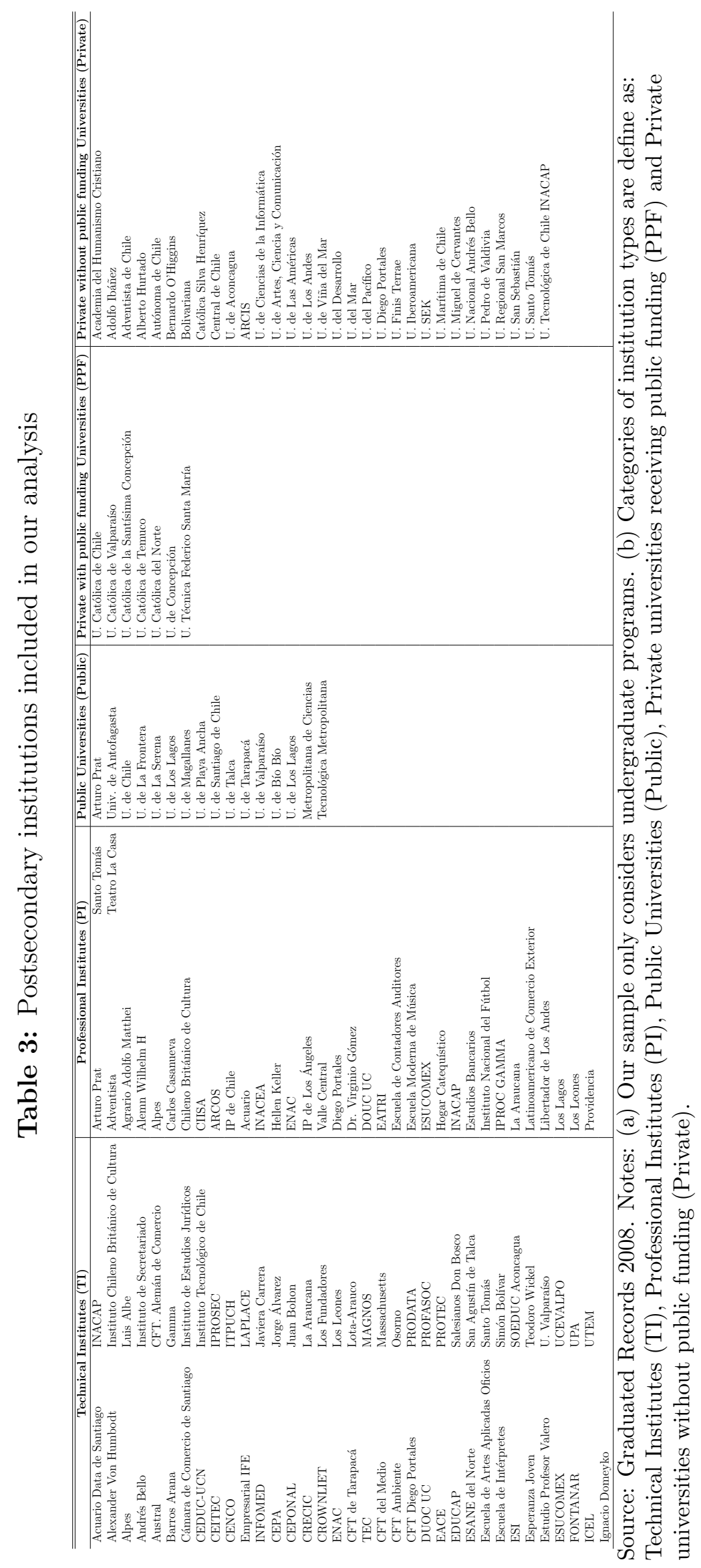


Table 4: Variables included in the empirical implementation of Multinomial Choice and Test Scores Equations

\begin{tabular}{|c|c|c|c|c|c|c|c|c|c|c|}
\hline \multirow[b]{2}{*}{ Variable } & \multicolumn{6}{|c|}{ "Educational Multinomial Choice Model } & \multicolumn{4}{|c|}{ Test Scores Equations } \\
\hline & TI & PI & Public & PPF & Private & C.Group & Language & Math & Geography & GPA \\
\hline Age (2008) & Yes & Yes & Yes & Yes & Yes & - & Yes & Yes & Yes & Yes \\
\hline Gender & Yes & Yes & Yes & Yes & Yes & - & Yes & Yes & Yes & Yes \\
\hline Mother with less than 8 years of schooling & - & - & - & - & - & - & - & - & - & - \\
\hline Mother with 8-11 years of schooling & Yes & Yes & Yes & Yes & Yes & - & Yes & Yes & Yes & Yes \\
\hline Mother with 12 years of schooling & Yes & Yes & Yes & Yes & Yes & - & Yes & Yes & Yes & Yes \\
\hline Mother with more than 12 years of schooling & Yes & Yes & Yes & Yes & Yes & - & Yes & Yes & Yes & Yes \\
\hline Family Income between 0-556 US/month & Yes & Yes & Yes & Yes & Yes & - & Yes & Yes & Yes & Yes \\
\hline Family Income between 557-1668 US/month & Yes & Yes & Yes & Yes & Yes & - & Yes & Yes & Yes & Yes \\
\hline Family Income between 1669-2800 US/month & Yes & Yes & Yes & Yes & Yes & - & Yes & Yes & Yes & Yes \\
\hline Family Income between 2801-3900 US/month & Yes & Yes & Yes & Yes & Yes & - & Yes & Yes & Yes & Yes \\
\hline Family Income between $>3900$ US/month & - & - & - & - & - & - & - & - & - & - \\
\hline Average Tuition Cost TI (2007) & Yes & - & - & - & - & - & - & - & - & - \\
\hline Average Tuition Cost PI (2007) & - & Yes & - & - & - & - & - & - & - & - \\
\hline Average Tuition Cost Public (2007) & - & - & Yes & - & - & - & - & - & - & - \\
\hline Average Tuition Cost PPF (2007) & - & - & - & Yes & - & - & - & - & - & - \\
\hline Average Tuition Cost Private (2007) & - & - & - & - & Yes & - & - & - & - & - \\
\hline Unobserved Ability & Yes & Yes & Yes & Yes & Yes & - & Yes & - & Yes & Yes \\
\hline Constant & Yes & Yes & Yes & Yes & Yes & - & Yes & Yes & - & Yes \\
\hline
\end{tabular}

Notes: (a) Categories of institution types are define as: Technical Institutes (TI), Professional Institutes (PI), Public Universities (Public), Private universities receiving public funding (PPF) and Private universities without public funding (Private). (b) Control group corresponds to students who took PSU in 2007 but who do not appear in enrollment records (2008 and 2009). (c) Gender is equal to 1 for male, 0 for female. (d) PSU scores are expressed as centiles of the whole distribution of PSU scores for each one of the years considered in the sample. As we described in the text, our sample considers individuals who took PSU during 2001 and 2005. Due the fact that PSU scores are not comparable across the time, we use a measure of relative academic performance of the students who took the test each year. 
Table 5: Variables included in the empirical implementation of Labor Market Outcome Equations

\begin{tabular}{lcccccc|cccccc}
\hline \hline & \multicolumn{9}{c|}{ Initial Earnings } & \multicolumn{4}{c}{ Growth Rates } \\
\multicolumn{1}{c}{ Variable } & TI & PI & Public & PPF & Private & C.Group & TI & PI & Public & PPF & Private & C.Group \\
\hline Age (2008) & Yes & Yes & Yes & Yes & Yes & Yes & Yes & Yes & Yes & Yes & Yes & Yes \\
Gender & Yes & Yes & Yes & Yes & Yes & Yes & Yes & Yes & Yes & Yes & Yes & Yes \\
Unobserved Ability & Yes & Yes & Yes & Yes & Yes & Yes & Yes & Yes & Yes & Yes & Yes & Yes \\
Constant & Yes & Yes & Yes & Yes & Yes & Yes & Yes & Yes & Yes & Yes & Yes & Yes \\
\hline
\end{tabular}

Notes: (a) Categories of institution types are define as: Technical Institutes (TI), Professional Institutes (PI), Public Universities (Public), Private universities receiving public funding (PPF) and Private universities without public funding (Private). (b) Control group corresponds to students who took PSU in 2007 but who do not appear in enrollment records (2008 and 2009). (c) Gender is equal to 1 for male, 0 for female. (d) PSU scores are expressed as centiles of the whole distribution of PSU scores for each one of the years considered in the sample. As we described in the text, our sample considers individuals who took PSU during 2001 and 2005. Due the fact that PSU scores are not comparable across the time, we use a measure of relative academic performance of the students who took the test each year. 
Table 6: Summary Statistics

\begin{tabular}{lcccc}
\hline \hline \multicolumn{1}{c}{ Variable } & Mean & Std. Dev. & Min. & Max. \\
\hline Language PSU & 0.385 & 0.676 & -1.476 & 3.993 \\
Math PSU & 0.439 & 0.832 & -1.851 & 4.514 \\
Geography PSU & 0.416 & 0.706 & -1.438 & 4.513 \\
High school GPA & 0.747 & 0.656 & -1.088 & 6.715 \\
Age (2008) & 22.62 & 2.523 & 18 & 30 \\
Male & 0.425 & 0.494 & 0 & 1 \\
Mother with less than 8 years of education & 0.151 & 0.358 & 0 & 1 \\
Mother with 8-11 years of education & 0.278 & 0.448 & 0 & 1 \\
Mother with12 years of education & 0.327 & 0.469 & 0 & 1 \\
Mother with more than 12 years of education & 0.241 & 0.428 & 0 & 1 \\
Family Income (0 - 556 dollars per month) & 0.622 & 0.484 & 0 & 1 \\
Family Income (557 - 1668 dollars per month) & 0.258 & 0.437 & 0 & 1 \\
Family Income (1669 - 2800 dollars per month) & 0.055 & 0.228 & 0 & 1 \\
Family Income (2801 - 3900 dollars per month) & 0.022 & 0.147 & 0 & 1 \\
Family Income (more than 3900 dollars per month) & 0.040 & 0.198 & 0 & 1 \\
Choice Indicator: TI & 0.056 & 0.231 & 0 & 1 \\
Choice Indicator: PI & 0.091 & 0.288 & 0 & 1 \\
Choice Indicator: Public & 0.139 & 0.346 & 0 & 1 \\
Choice Indicator: PPF & 0.086 & 0.280 & 0 & 1 \\
Choice Indicator: Private & 0.169 & 0.374 & 0 & 1 \\
Choice Indicator: Control Group & 0.456 & 0.498 & 0 & 1 \\
Annual Tuition: TI & 0.792 & 0.050 & 0.752 & 0.963 \\
Annual Tuition: PI & 0.941 & 0.056 & 0.829 & 0.985 \\
Annual Tuition: Public & 1.476 & 0.252 & 10.105 & 19.474 \\
Annual Tuition: PPF & 2.026 & 0.653 & 0.821 & 2.736 \\
Annual Tuition: Private & 1.604 & 0.237 & 10.105 & 1.830 \\
Monthly Average Earnings (2008) & 12.062 & 0.965 & 9,510 & 14.455 \\
Monthly Average Earnings (2010) & 12.531 & 0.997 & 9.598 & 14.566 \\
Growth Rate of Earnings 2008-2010 & 0.042 & 0.079 & -0.298 & 0.462 \\
\hline
\end{tabular}

Notes: Sample size 57,159. As described in the text, our sample considers individuals who took PSU during 2001 and 2005. Due the fact that PSU scores are not comparable across the time, we use a measure of relative academic performance: percentiles within each year. Also, considering that PSU scores are used as dependent variable in linear equations we use the following transformation. Let $x$ denote the PSU percentile. Thus, we use $g(x)=\ln (x / 1-x)$. Categories of institution types are define as: Two-year degrees provided by Technical Institutes (TI), four-year degrees obtained in Professional Institutes (PI) and five-year degrees from Public Universities (Public), Private universities receiving public funding (PPF) and Private universities without public funding (Private). Control Group corresponds to students who took PSU in 2007 but who do not appear in enrollment records (2008 and 2009). Annual Tuition costs correspond to the annual cost of each one of the institution types conditional on the alternative chosen by the individuals (in million of chilean pesos). 
Table 7: Schooling Choice Model Estimates

\begin{tabular}{lccccc}
\hline \hline \multicolumn{1}{c}{ Variable } & TI & PI & Public & PPF & Private \\
& $(1)$ & $(2)$ & $(3)$ & $(4)$ & $(5)$ \\
\hline Age (2008) & 0.553 & 0.635 & 0.862 & 0.883 & 0.748 \\
& $(0.006)$ & $(0.006)$ & $(0.008)$ & $(0.009)$ & $(0.006)$ \\
Male & -0.314 & -0.157 & -0.701 & -0.672 & -0.705 \\
& $(0.027)$ & $(0.025)$ & $(0.028)$ & $(0.034)$ & $(0.024)$ \\
Mother with 8 -11 years of education & 0.259 & 0.317 & 0.380 & 0.436 & 0.474 \\
& $(0.042)$ & $(0.041)$ & $(0.050)$ & $(0.061)$ & $(0.045)$ \\
Mother with 12 years of education & 0.234 & 0.374 & 0.641 & 0.728 & 0.780 \\
& $(0.042)$ & $(0.040)$ & $(0.048)$ & $(0.057)$ & $(0.042)$ \\
Mother with more than 12 years of education & 0.183 & 0.426 & 1.002 & 1.339 & 1.100 \\
& $(0.052)$ & $(0.049)$ & $(0.056)$ & $(0.067)$ & $(0.049)$ \\
Family Income (0 - 556 dollars per month) & 0.093 & -0.117 & -0.209 & -1.422 & -1.809 \\
& $(0.112)$ & $(0.088)$ & $(0.096)$ & $(0.096)$ & $(0.073)$ \\
Family Income (557 - 1668 dollars per month) & 0.403 & 0.390 & 0.382 & -0.769 & -0.836 \\
& $(0.112)$ & $(0.087)$ & $(0.095)$ & $(0.094)$ & $(0.072)$ \\
Family Income (1669 - 2800 dollars per month) & 0.209 & 0.350 & 0.413 & -0.486 & -0.389 \\
& $(0.131)$ & $(0.103)$ & $(0.110)$ & $(0.111)$ & $(0.087)$ \\
Family Income (2801 - 3900 dollars per month) & 0.236 & 0.400 & 0.142 & -0.319 & -0.182 \\
& $(0.166)$ & $(0.128)$ & $(0.134)$ & $(0.137)$ & $(0.106)$ \\
Annual Tuition Costs & 0.190 & 1.620 & -0.511 & -0.608 & 0.437 \\
& $(0.217)$ & $(0.187)$ & $(0.041)$ & $(0.020)$ & $(0.041)$ \\
Unobserved Ability & -0.108 & 0.167 & 2.984 & 3.421 & 1.187 \\
Constant & $(0.046)$ & $(0.039)$ & $(0.044)$ & $(0.047)$ & $(0.036)$ \\
& -12.851 & -15.857 & -18.884 & -18.599 & -16.043 \\
& $(0.291)$ & $(0.290)$ & $(0.265)$ & $(0.296)$ & $(0.238)$ \\
\hline
\end{tabular}

Notes: (a) Annual Tuition corresponds to the annual cost of each one of the choices conditional to the alternative selected by the individuals. (b) Categories of institution types are define as: Two-year degrees provided by Technical Institutes (TI), four-year degrees obtained in Professional Institutes (PI) and five-year degrees from Public Universities (Public), Private universities receiving public funding (PPF) and Private universities without public funding (Private). (c) CG corresponds to our control group (students who took PSU in 2007 but who do not appear in enrollment records in 2008 and 2009). Standard errors in parentheses. 
Table 8: Measurement system

\begin{tabular}{|c|c|c|c|c|}
\hline Variable & $\begin{array}{c}\text { Language } \\
(1)\end{array}$ & $\begin{array}{c}\text { Math } \\
(2)\end{array}$ & $\begin{array}{c}\text { Geography } \\
(3)\end{array}$ & $\begin{array}{c}\text { GPA } \\
(4)\end{array}$ \\
\hline \multirow{2}{*}{ Age (2008) } & 0.078 & 0.090 & 0.080 & 0.039 \\
\hline & $(0.001)$ & $(0.001)$ & $(0.001)$ & $(0.001)$ \\
\hline \multirow[t]{2}{*}{ Male } & -0.025 & 0.132 & 0.105 & -0.200 \\
\hline & $(0.004)$ & $(0.005)$ & $(0.005)$ & $(0.005)$ \\
\hline \multirow[t]{2}{*}{ Mother with 8-11 years of education } & 0.064 & 0.051 & 0.039 & -0.035 \\
\hline & $(0.007)$ & $(0.008)$ & $(0.008)$ & $(0.008)$ \\
\hline \multirow[t]{2}{*}{ Mother with 12 years of education } & 0.157 & 0.132 & 0.107 & -0.027 \\
\hline & $(0.007)$ & $(0.008)$ & $(0.008)$ & $(0.008)$ \\
\hline \multirow[t]{2}{*}{ Mother with more than 12 years of education } & 0.365 & 0.361 & 0.295 & 0.091 \\
\hline & $(0.008)$ & $(0.010)$ & $(0.009)$ & $(0.009)$ \\
\hline \multirow[t]{2}{*}{ Family Income ( 0 - 556 dollars per month) } & -0.483 & -0.809 & -0.472 & -0.296 \\
\hline & $(0.014)$ & $(0.016)$ & $(0.014)$ & $(0.015)$ \\
\hline \multirow{2}{*}{ Family Income (557 - 1668 dollars per month) } & -0.342 & -0.634 & -0.347 & -0.239 \\
\hline & $(0.013)$ & $(0.016)$ & $(0.014)$ & $(0.014)$ \\
\hline \multirow[t]{2}{*}{ Family Income (1669 - 2800 dollars per month) } & -0.174 & -0.375 & -0.173 & -0.104 \\
\hline & $(0.015)$ & $(0.019)$ & $(0.016)$ & $(0.017)$ \\
\hline \multirow[t]{2}{*}{ Family Income (2801 - 3900 dollars per month) } & -0.097 & -0.172 & -0.097 & -0.058 \\
\hline & $(0.019)$ & $(0.023)$ & $(0.021)$ & $(0.021)$ \\
\hline \multirow[t]{2}{*}{ Unobserved Ability } & 1.000 & 1.134 & 1.042 & 0.807 \\
\hline & $(0.000)$ & $(0.006)$ & $(0.005)$ & $(0.006)$ \\
\hline \multirow[t]{2}{*}{ Constant } & -1.114 & -1.107 & -1.151 & 0.198 \\
\hline & $(0.026)$ & $(0.032)$ & $(0.027)$ & $(0.029)$ \\
\hline
\end{tabular}

Notes: PSU scores are expressed as percentiles of the year-specific distribution of PSU scores. As we described in the text, our sample considers individuals who took PSU during 2001 and 2005. Due the fact that PSU scores are not comparable across the time, we use a measure of relative academic performance of the students who took the test each year. Also, considering that PSU scores are used as dependent variables in linear equations we the following transformation. Let $x$ a variable that took values in the range [0.1] and $g(\cdot)$ a monotonic transformation, then $g(x)=\ln (x / 1-x)$. Standard errors in parentheses. 
Table 9: Labor Market Outcomes Estimates. Initial Earnings and Growth Rates

\begin{tabular}{|c|c|c|c|c|c|c|c|c|c|c|c|c|}
\hline \multirow{2}{*}{ Variable } & \multicolumn{6}{|c|}{ Level } & \multicolumn{5}{|c|}{ Growth rate } & \multirow[b]{2}{*}{$\begin{array}{l}\text { CG } \\
(12)\end{array}$} \\
\hline & $\begin{array}{l}\text { TI } \\
(1)\end{array}$ & $\begin{array}{l}\mathbf{P I} \\
(2)\end{array}$ & $\begin{array}{c}\text { Public } \\
(3)\end{array}$ & $\begin{array}{c}\mathbf{P P F} \\
(4)\end{array}$ & $\begin{array}{c}\text { Private } \\
(5)\end{array}$ & $\begin{array}{l}\mathbf{C G} \\
(6)\end{array}$ & $\begin{array}{l}\text { TI } \\
(7)\end{array}$ & $\begin{array}{l}\mathbf{P I} \\
(8)\end{array}$ & $\begin{array}{c}\text { Public } \\
(9)\end{array}$ & $\begin{array}{c}\mathbf{P P F} \\
(10)\end{array}$ & $\begin{array}{c}\text { Private } \\
(11)\end{array}$ & \\
\hline Age (2008) & 0.021 & 0.050 & 0.033 & 0.016 & 0.044 & 0.010 & 0.000 & -0.002 & -0.002 & -0.002 & -0.007 & -0.002 \\
\hline Male & $\begin{array}{c}(0.011) \\
0.342 \\
(0.037)\end{array}$ & $\begin{array}{c}(0.009) \\
0.297 \\
(0.029)\end{array}$ & $\begin{array}{c}(0.008) \\
0.300 \\
(0.026)\end{array}$ & $\begin{array}{c}(0.010) \\
0.271 \\
(0.031)\end{array}$ & $\begin{array}{c}(0.008) \\
0.096 \\
(0.024)\end{array}$ & $\begin{array}{c}(0.004) \\
0.297 \\
(0.013)\end{array}$ & $\begin{array}{c}(0.001) \\
0.001 \\
(0.004)\end{array}$ & $\begin{array}{c}(0.001) \\
0.004 \\
(0.003)\end{array}$ & $\begin{array}{c}(0.001) \\
0.003 \\
(0.003)\end{array}$ & $\begin{array}{c}(0.001) \\
0.006 \\
(0.004)\end{array}$ & $\begin{array}{c}(0.001) \\
0.001 \\
(0.003)\end{array}$ & $\begin{array}{c}(0.000) \\
0.005 \\
(0.001)\end{array}$ \\
\hline Unobserved ability & $\begin{array}{l}0.257 \\
(0.069)\end{array}$ & $\begin{array}{c}0.328 \\
(0.050)\end{array}$ & $\begin{array}{l}0.314 \\
(0.030)\end{array}$ & $\begin{array}{l}0.343 \\
(0.035)\end{array}$ & $\begin{array}{l}0.369 \\
(0.034)\end{array}$ & $\begin{array}{c}0.072 \\
(0.025)\end{array}$ & $\begin{array}{c}0.000 \\
(0.007)\end{array}$ & $\begin{array}{l}0.001 \\
(0.005)\end{array}$ & $\begin{array}{l}0.004 \\
(0.003)\end{array}$ & $\begin{array}{l}0.004 \\
(0.004)\end{array}$ & $\begin{array}{l}-0.002 \\
(0.004)\end{array}$ & $\begin{array}{l}-0.006 \\
(0.003)\end{array}$ \\
\hline Constant & $\begin{array}{l}11.934 \\
(0.252)\end{array}$ & $\begin{array}{l}11.441 \\
(0.219)\end{array}$ & $\begin{array}{l}12.029 \\
(0.205)\end{array}$ & $\begin{array}{l}12.513 \\
(0.260)\end{array}$ & $\begin{array}{l}11.864 \\
(0.186)\end{array}$ & $\begin{array}{l}11.677 \\
(0.084)\end{array}$ & $\begin{array}{l}0.050 \\
(0.029)\end{array}$ & $\begin{array}{l}0.101 \\
(0.023)\end{array}$ & $\begin{array}{l}0.108 \\
(0.021)\end{array}$ & $\begin{array}{l}0.097 \\
(0.027)\end{array}$ & $\begin{array}{l}0.232 \\
(0.021)\end{array}$ & $\begin{array}{c}0.056 \\
(0.009)\end{array}$ \\
\hline
\end{tabular}

Notes: (a) We estimate labor marker outcomes linear regressions taking as dependent variables the natural logarithm of the average wage observed in 2008 (equation (4)) and the growth rate of average wage between 2008 and 2010 (equation (5)). (b) Categories of institution types are defined as: Technical Institutes (TI), Professional Institutes (PI), Public Universities (Public), Private Universities with access to public funding (PPF) and Private Universities without public funding (Private). (c) CG corresponds to the control group (students who took PSU in 2007 but who do not appear in enrollment records in 2008 and 2009). Standard errors in parentheses. 
Table 10: Estimated treatment effect on the treated: $T T_{j}^{0}$ and $T T_{j}^{k}$

\begin{tabular}{|c|c|c|c|c|c|c|c|c|}
\hline \multirow[b]{2}{*}{ Choice } & \multicolumn{4}{|c|}{$T T_{j}^{0}$} & \multicolumn{4}{|c|}{$T T_{j}^{k}$} \\
\hline & $\Delta_{j}^{0}$ & $r_{j}^{0}$ & $\operatorname{Pr}\left(r_{j}^{0}<0\right)$ & $\operatorname{Pr}\left(r_{j}^{0}<-10 \%\right)$ & $\Delta_{j}^{k}$ & $r_{j}^{k}$ & $\operatorname{Pr}\left(r_{j}^{k}<0\right)$ & $\operatorname{Pr}\left(r_{j}^{k}<-10 \%\right)$ \\
\hline Two-year degree (TI) & 26.6 & $29.0 \%$ & $41.9 \%$ & $38.2 \%$ & 2.6 & $13.8 \%$ & $46.4 \%$ & $43.1 \%$ \\
\hline Four-year degree (PI) & 37.5 & $31.0 \%$ & $42.1 \%$ & $39.0 \%$ & 8.3 & $6.8 \%$ & $48.1 \%$ & $45.1 \%$ \\
\hline Five-year degree (Public) & 62.5 & $54.5 \%$ & $37.2 \%$ & $33.9 \%$ & 4.7 & $3.8 \%$ & $48.9 \%$ & $46.1 \%$ \\
\hline Five-year degree (PPF) & 75.7 & $71.3 \%$ & $34.9 \%$ & $32.2 \%$ & 6.2 & $9.2 \%$ & $47.7 \%$ & $45.0 \%$ \\
\hline Five-year degree (Private) & 48.3 & $34.5 \%$ & $41.9 \%$ & $39.1 \%$ & 14.3 & $3.8 \%$ & $49.1 \%$ & $46.4 \%$ \\
\hline
\end{tabular}

Notes: $T T_{j}^{0}$ and $T T_{j}^{k}$ in thousands of dollars. (a) Categories of institution types are defined as: Technical Institutes (TI), Professional Institutes (PI), Public Universities (Public), Private Universities with access to public funding (PPF) and Private Universities without public funding (Private).

(b)Let $P V_{0}$ corresponds to the financial benefits or losses (that is, excluding psychic costs or benefits) of choosing not enrolling in any postsecondary degree and $P V_{j}$ the economic net benefits of choosing degree $j \in \mathcal{J}$ (see equations 9 and 10). One way of estimating agent's economic benefits of postsecondary education is given by:

$$
\begin{aligned}
\Delta_{j}^{0} & =P V_{j}-P V_{0} \\
r_{j}^{0} & =\left(P V_{j}-P V_{0}\right) / P V_{0}
\end{aligned}
$$

On the other hand, let

$$
\begin{aligned}
& j^{*}=\operatorname{argmax}_{j \in \mathcal{J}}\left\{V_{j}\right\} \\
& k^{*}=\operatorname{argmax}_{k \in \mathcal{J} \mid-j^{*}}\left\{V_{k}\right\}
\end{aligned}
$$

be the first and second choice, respectively. Then $D_{k \in \mathcal{J} \mid-j}=1$ if $k$ is the first choice in $\mathcal{J}$ excluding $j^{*}$. Let $P V_{j}$ and $P V_{k}$ the corresponding net economic benefits. Therefore, it is possible to define the following expressions:

$$
\begin{aligned}
\Delta_{j}^{k} & =P V_{j}-P V_{k} \\
r_{j}^{k} & =\left(P V_{j}-P V_{k}\right) / P V_{k}
\end{aligned}
$$

Finally, $\operatorname{Pr}(A)$ denotes the probability of event $A$. 


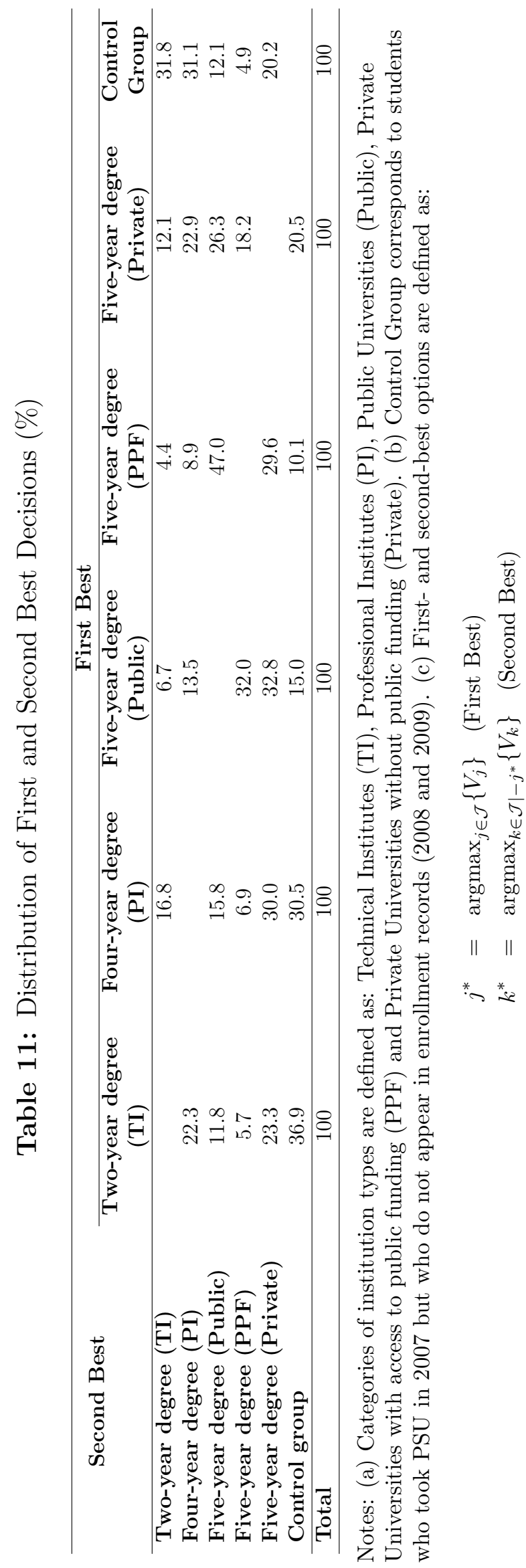


Table 12: Distribution of schooling choices after a $10 \%$ reduction in annual tuition costs

\begin{tabular}{lccccccc}
\hline \hline $\begin{array}{c}\text { Choice } \\
\text { (Original/New) }\end{array}$ & TI & PI & Public & PPF & Private & CG & Total \\
$(2)$ & $(3)$ & $(4)$ & $(5)$ & $(6)$ & $(7)$ \\
\hline TI & 5,339 & 0 & 94 & 55 & 0 & 49 & $\mathbf{5 , 5 3 7}$ \\
PI & 204 & 7,570 & 428 & 222 & 231 & 503 & $\mathbf{9 , 1 5 8}$ \\
Public & 0 & 0 & 13,262 & 144 & 0 & 0 & $\mathbf{1 3 , 4 0 6}$ \\
PPF & 0 & 0 & 9 & 8,019 & 0 & 0 & $\mathbf{8 , 0 2 8}$ \\
Private & 110 & 0 & 618 & 479 & 16,469 & 268 & $\mathbf{1 7 , 9 4 0}$ \\
CG & 5,662 & 0 & 179 & 126 & 0 & 45,617 & $\mathbf{4 5 , 9 3 1}$ \\
\hline Total & $\mathbf{5 , 6 6 2}$ & $\mathbf{7 , 5 7 0}$ & $\mathbf{1 4 , 5 9 0}$ & $\mathbf{9 , 0 4 1}$ & $\mathbf{1 6 , 7 0 0}$ & $\mathbf{4 6 , 4 3 7}$ & $\mathbf{1 0 0 , 0 0 0}$ \\
\hline
\end{tabular}

Notes: (a) We present the number of graduates coming from different types of postsecondary degrees (and individuals not pursuing postsecondary education) before (in columns) and after (in rows) the reduction in tuition. (b) Categories of institution types are defined as: Technical Institutes (TI), Professional Institutes (PI), Public Universities (Public), Private Universities with access to public funding (PPF) and Private Universities without public funding (Private). (c) CG corresponds to our control group (students who took PSU in 2007 but who do not appear in enrollment records in 2008 and 2009). 


\section{Figure 1: Distribution of Enrollment by PSU Quintiles}

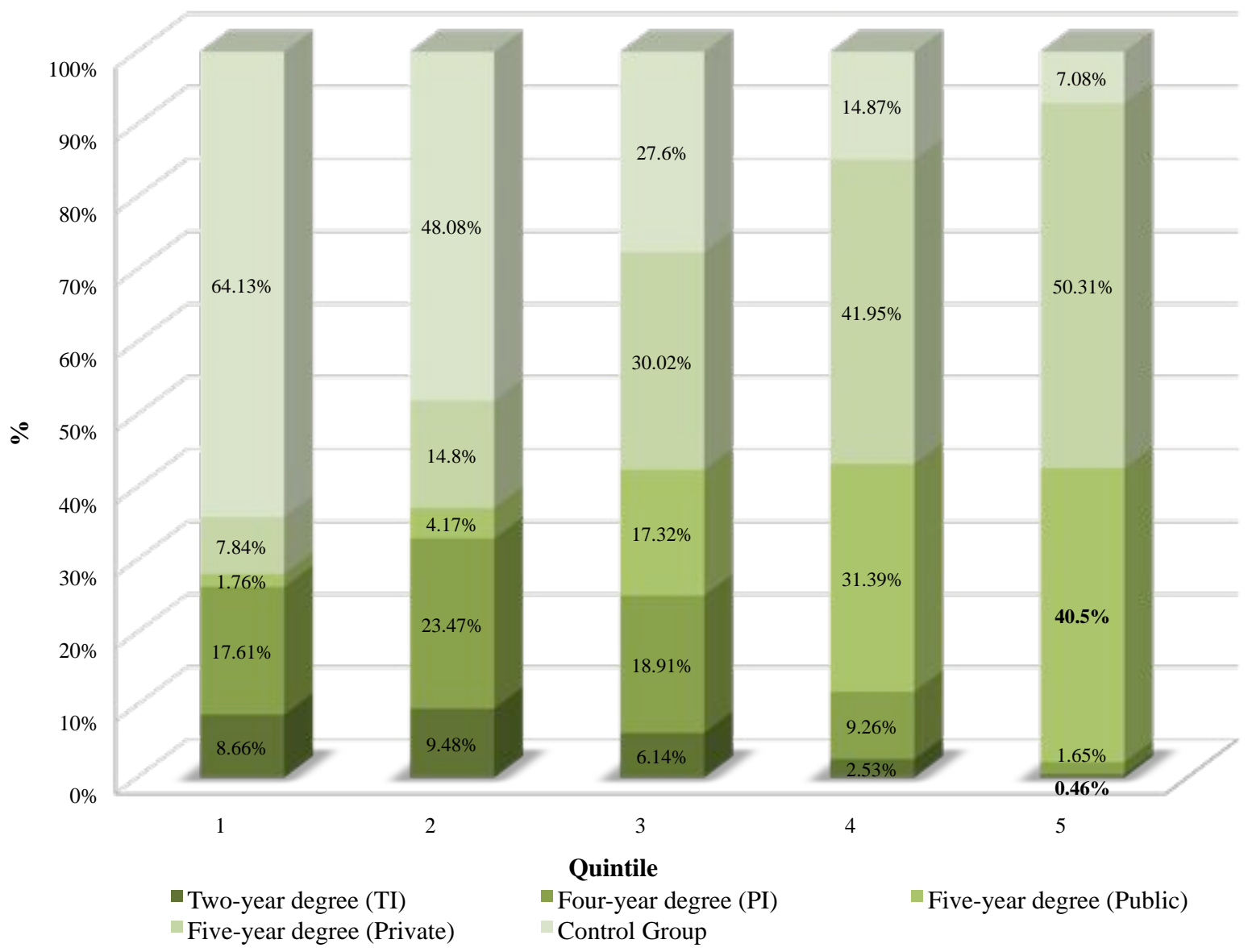

Source: Universe of individuals taking PSU 2007. Enrollment status in 2008 is obtained from administrative records from the tertiary education system. Notes: (a) Categories of institution types are defined as: Technical Institutes (TI), Professional Institutes (PI), Public Universities (Public), Private Universities with access to public funding and Private Universities without public funding (Private). (b) Control Group corresponds to students who took PSU in 2007 but who do not appear in enrollment records (2008 and 2009). (c) PSU's quintiles correspond to: 1: <409 pts., 2: 410-470 pts., 3: 470-526 pts., 4: 526-590 pts, 5: 590-838 pts. 
Figure 2: Enrollment by Type of Postsecondary Institution and Family Income

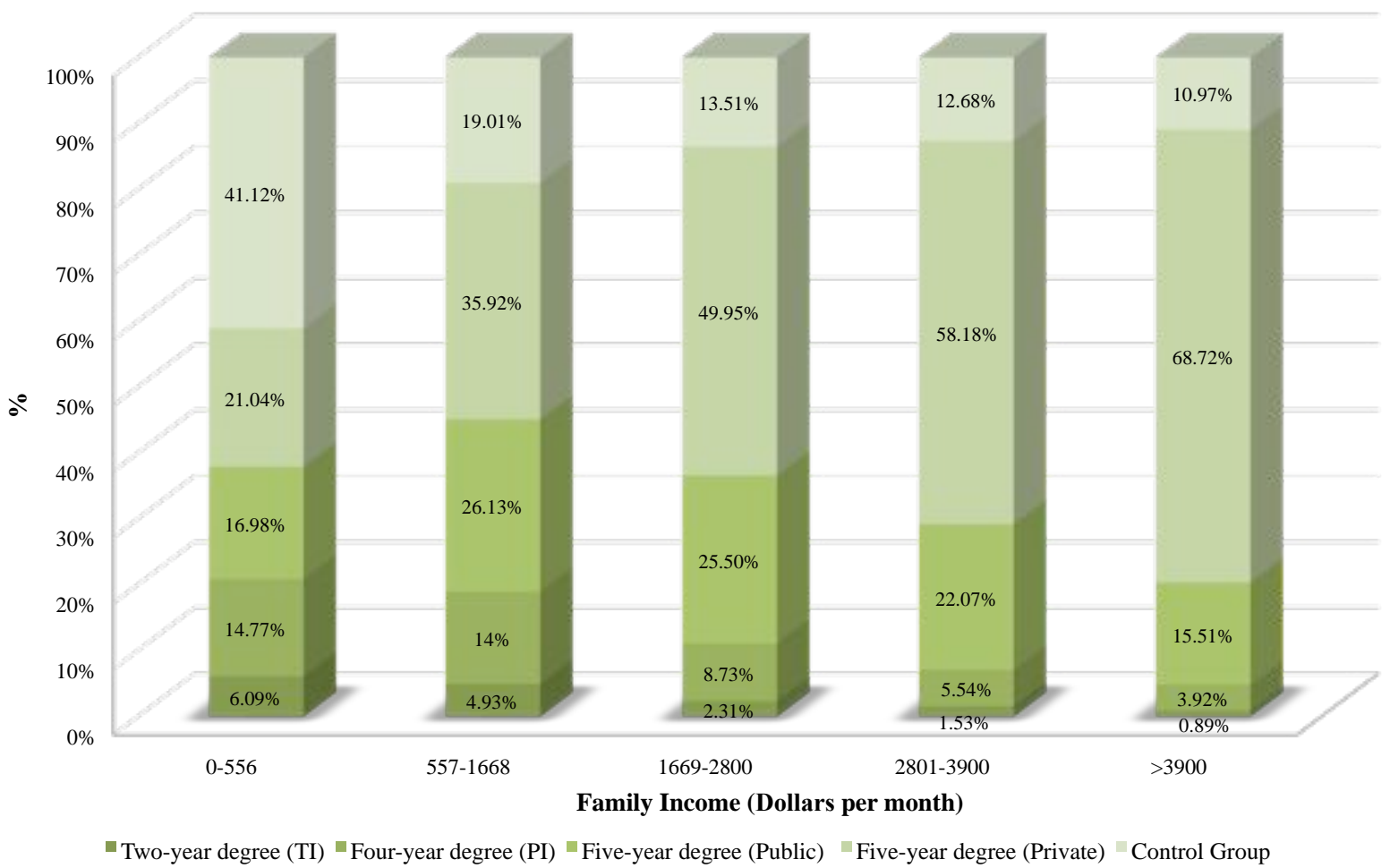

Source: Universe of individuals taking PSU 2007. Enrollment status in 2008 is obtained from administrative records from the tertiary education system. Notes: (a) Categories of institution types are defined as: Technical Institutes (TI), Professional Institutes (PI), Public Universities (Public), Private Universities with access to public funding and Private Universities without public funding (Private). (b) Control Group corresponds to students who took PSU in 2007 but who do not appear in enrollment records (2007 and 2008). (c) Family Income corresponds to the monthly income selfreported by the students at the moment of PSU. 
Figure 3: Enrollment Type of Postsecondary Institution and Mother's Education

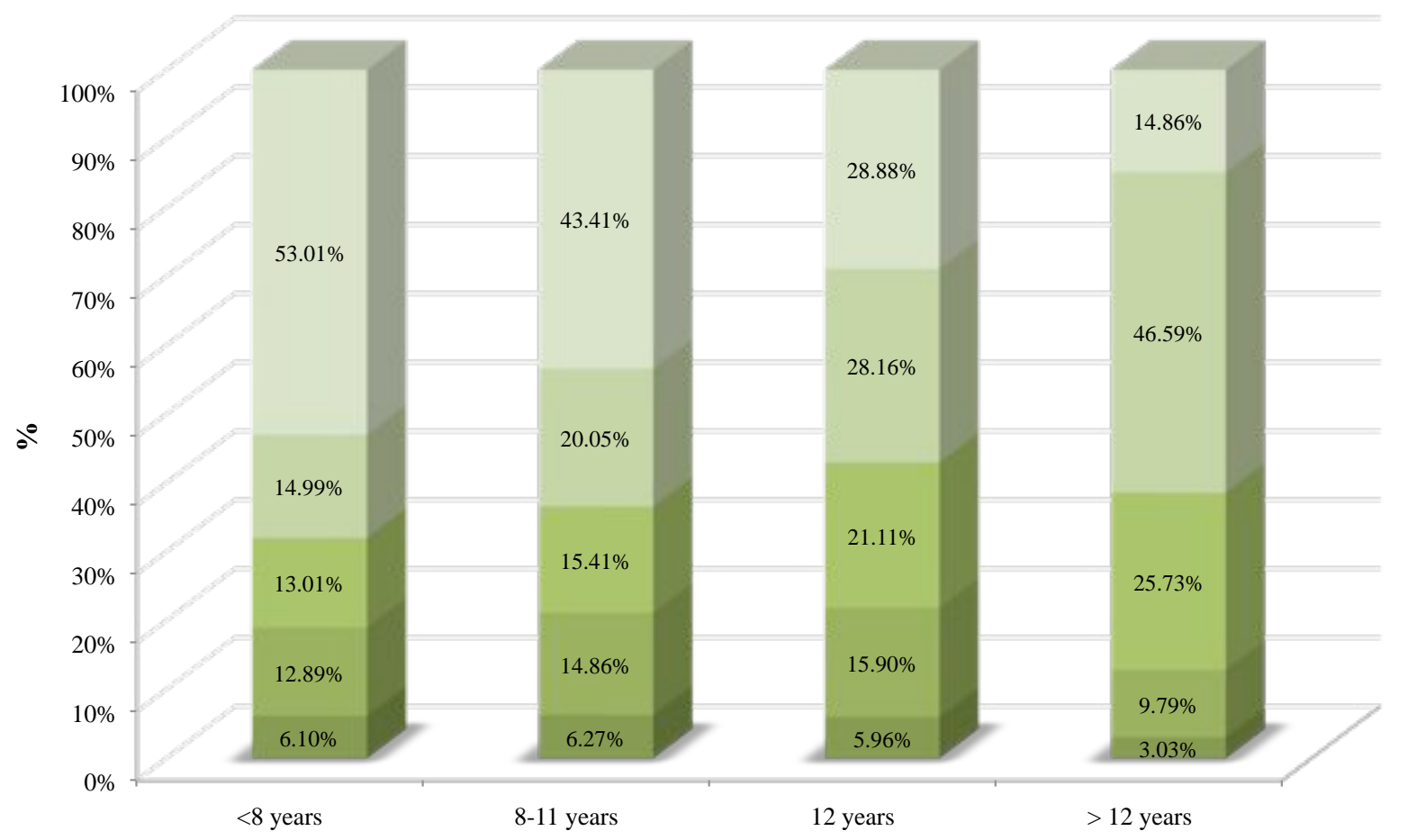

Mother's Education

- Two-year degree (TI) $\quad$ Four-year degree (PI) $\quad$ Five-year degree (Public)

Five-year degree (Private) Control Group

Source: Universe of individuals taking PSU 2007. Enrollment status in 2008 is obtained from administrative records from the tertiary education system. Notes: (a) Categories of institution types are defined as: Technical Institutes (TI), Professional Institutes (PI), Public Universities (Public), Private Universities with access to public funding and Private Universities without public funding (Private). (b) Control Group corresponds to students who took PSU in 2007 but who do not appear in enrollment records (2008). 
Figure 4: Average monthly earnings by type of degree, 2008 and 2010

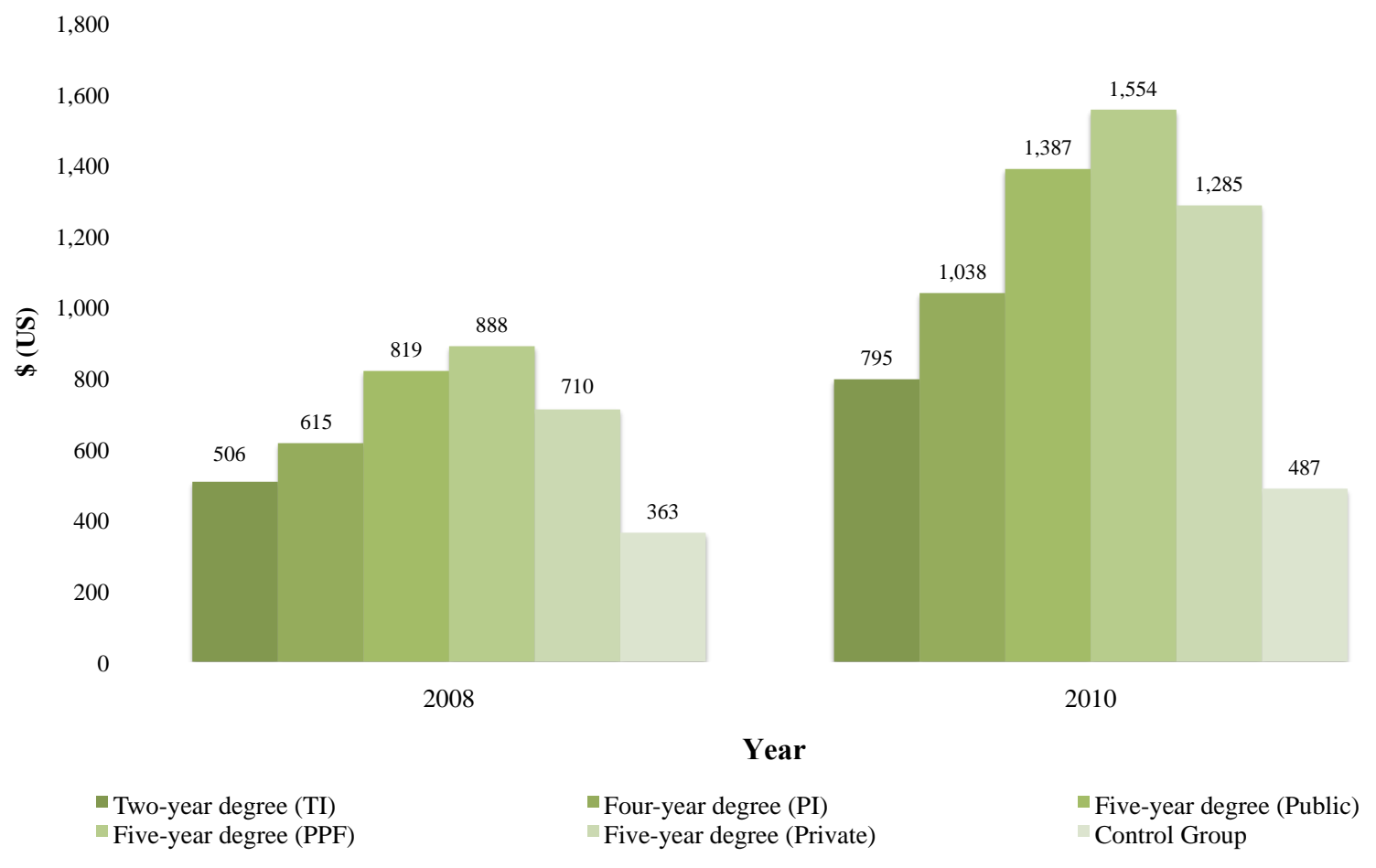

Source: Data from the Unemployment Insurance system. Individual-level data on postsecondary degrees from the Chilean Ministry of Education. Notes: (a) We show average earnings at graduation year (2008) and two years later (2010). (b) Categories of institution types are defined as: Technical Institutes (TI), Professional Institutes (PI), Public Universities (Public), Private Universities with access to public funding (PPF) and Private Universities without public funding (Private). (c) Control Group corresponds to students who took PSU in 2007 but who do not appear in enrollment records (2007 and 2008). 
Figure 5: Estimated Distribution of Latent Ability

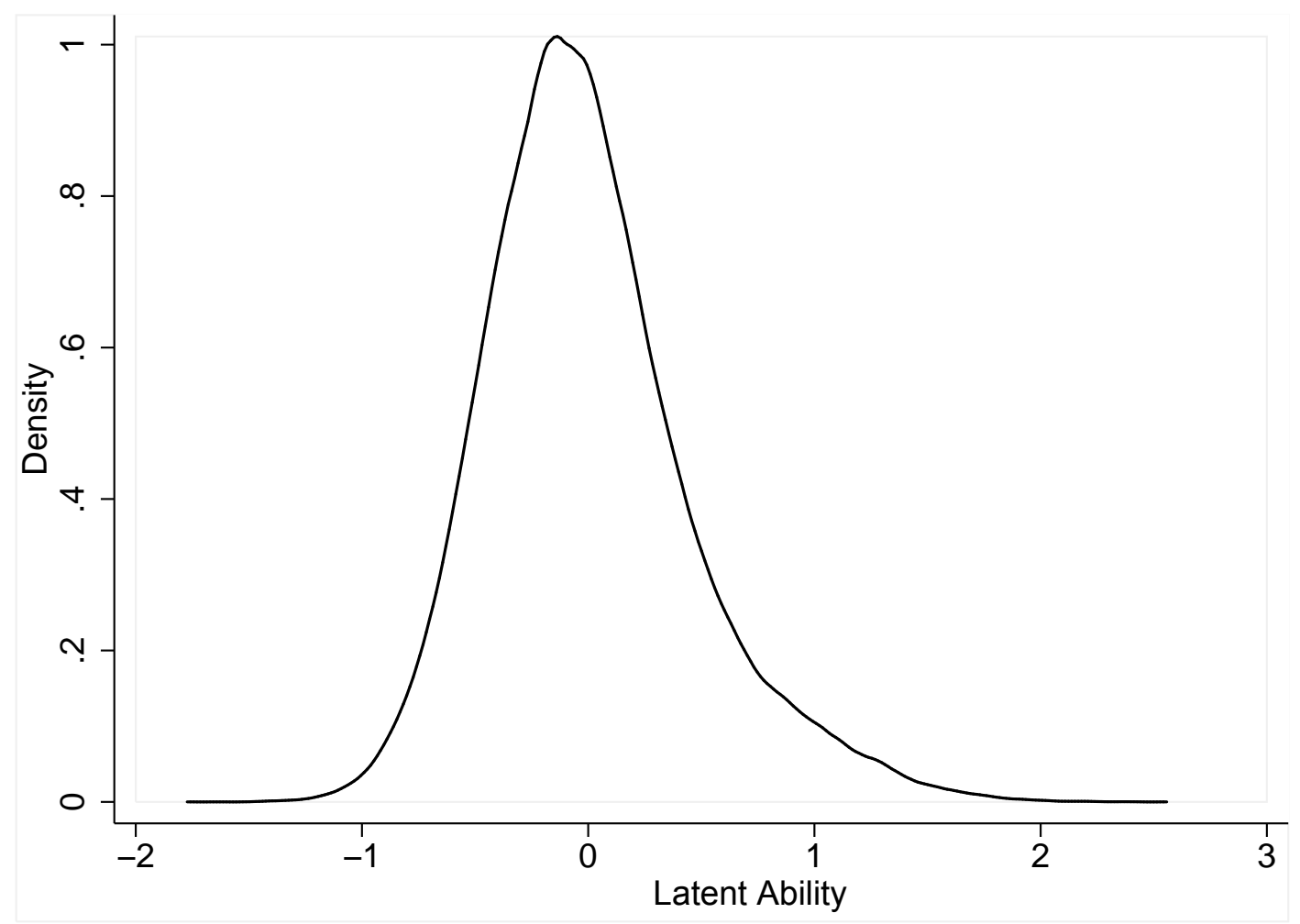

$$
\begin{aligned}
f \sim p_{1} N\left(\mu_{1}, \sigma_{1}^{2}\right) & +p_{2} N\left(\mu_{2}, \sigma_{2}^{2}\right) \\
\text { where } & \\
\left(\mu_{1}, \mu_{2}\right)= & (0.406,-0.141) \\
\left(1 / \sigma_{1}^{2}, 1 / \sigma_{2}^{2}\right)= & (3.464,9.177) \\
\left(p_{1}, p_{2}\right)= & (0.259,0.741) \\
\sigma^{2}= & 0.212
\end{aligned}
$$

Notes: The factor is simulated from the estimates of the model. Simulated data contains 100,000 observations. 
Figure 6: Goodness of Fit: Schooling decisions

Actual versus model simulated samples

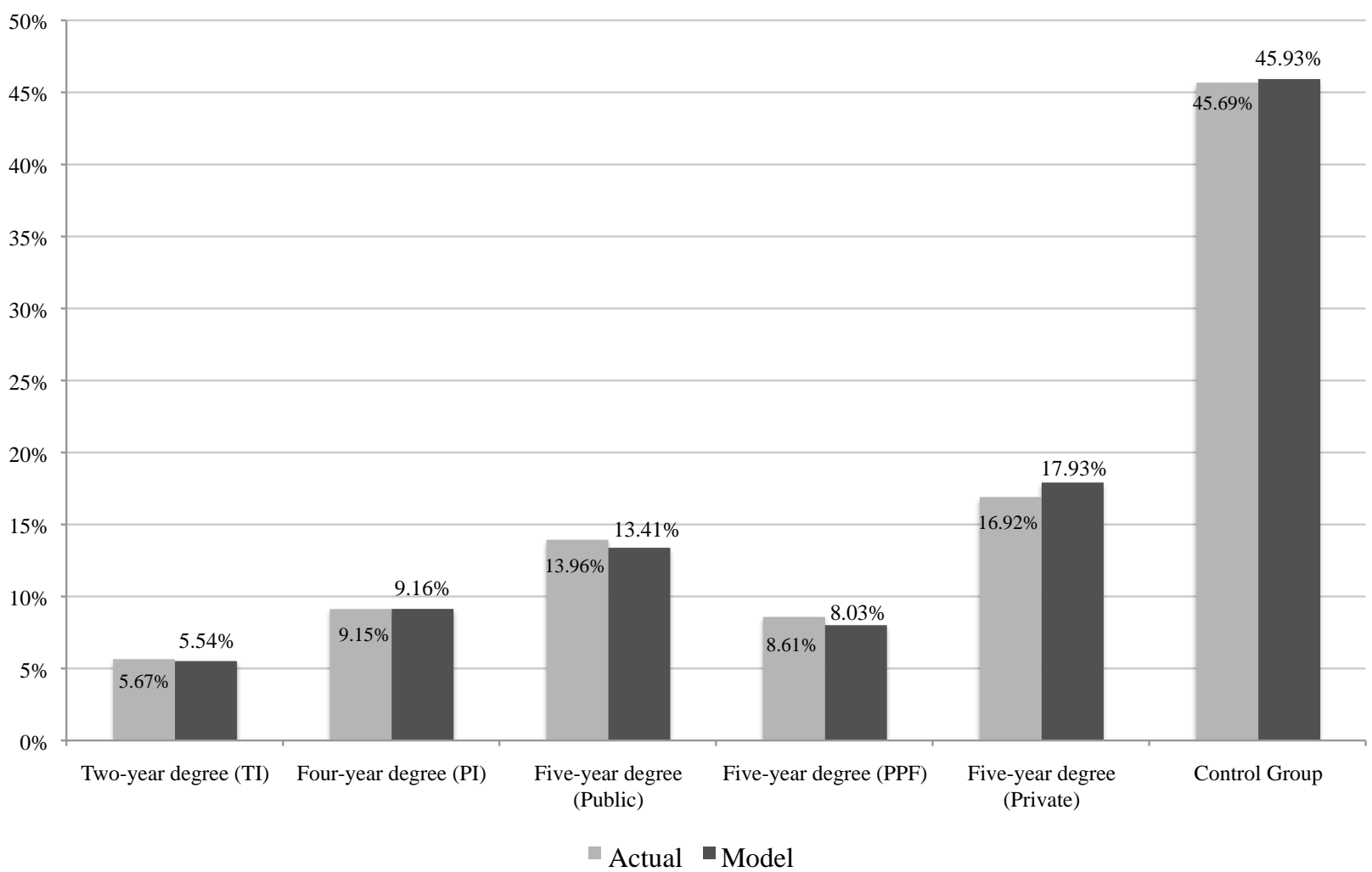

Notes: (a) Categories of institution types are defined as: Technical Institutes (TI), Professional Institutes (PI), Public Universities (Public), Private Universities with access to public funding (PPF) and Private Universities without public funding (Private). (b) Control Group corresponds to students who took PSU in 2007 but who do not appear in enrollment records (2008 and 2009). (c) Goodnessof-fit tests for the Null Hypothesis Model = Data are presented in appendix. 
Figure 7: Goodness of Fit: Average Monthly Earnings (US 2010) Actual versus model simulated samples

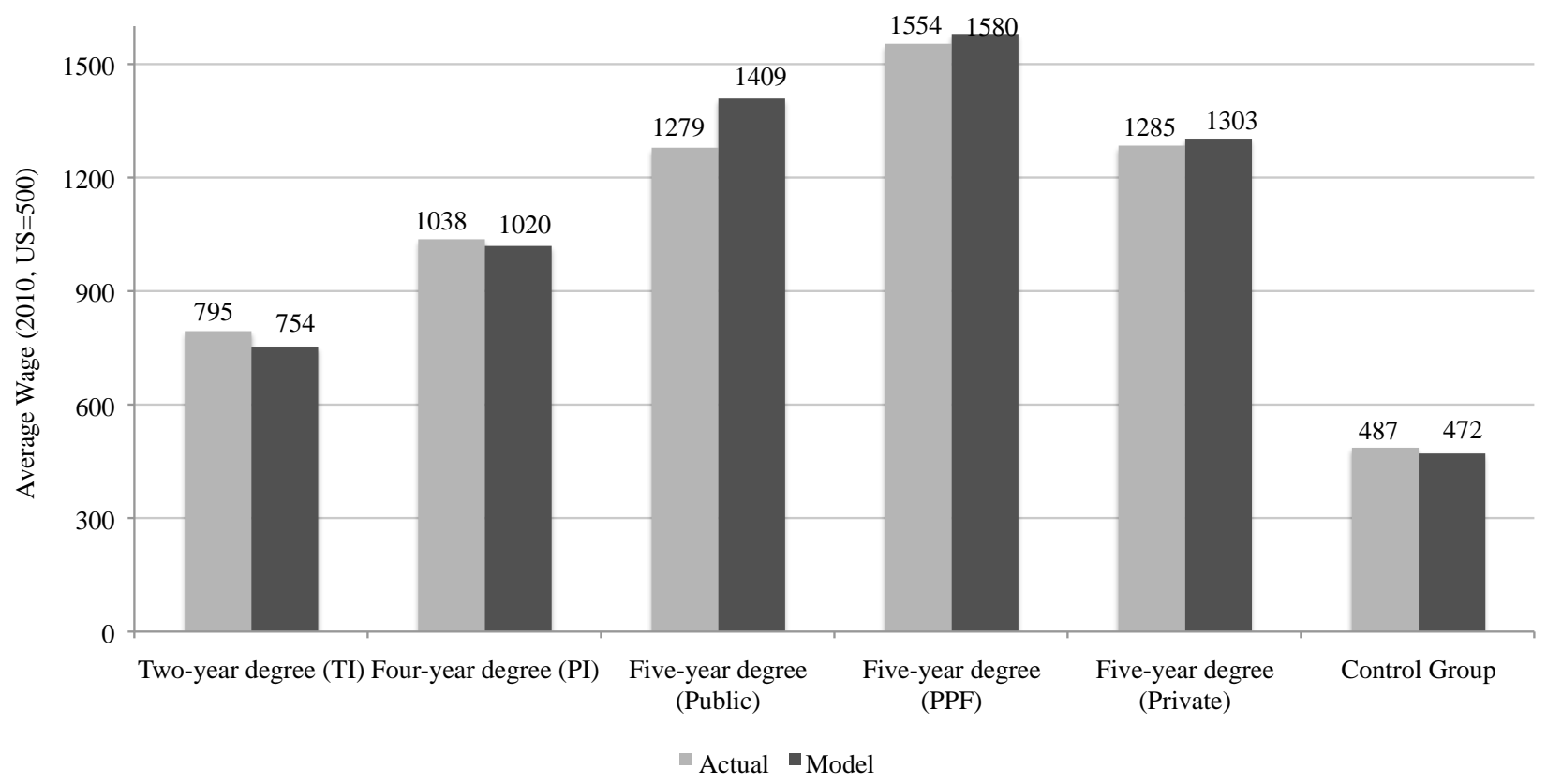

Notes: (a) Categories of institution types are defined as: Technical Institutes (TI), Professional Institutes (PI), Public Universities (Public), Private Universities with access to public funding (PPF) and Private Universities without public funding (Private). (b) Control Group corresponds to students who took PSU in 2007 but who do not appear in enrollment records (2008 and 2009). (c) The actual data (Actual) contains 57,159 observations while the simulated data (model) contains 100,000 observations generated from Model's estimates. 
Figure 8: Goodness of Fit: Annual growth rates of monthly earnings Actual versus model simulated samples

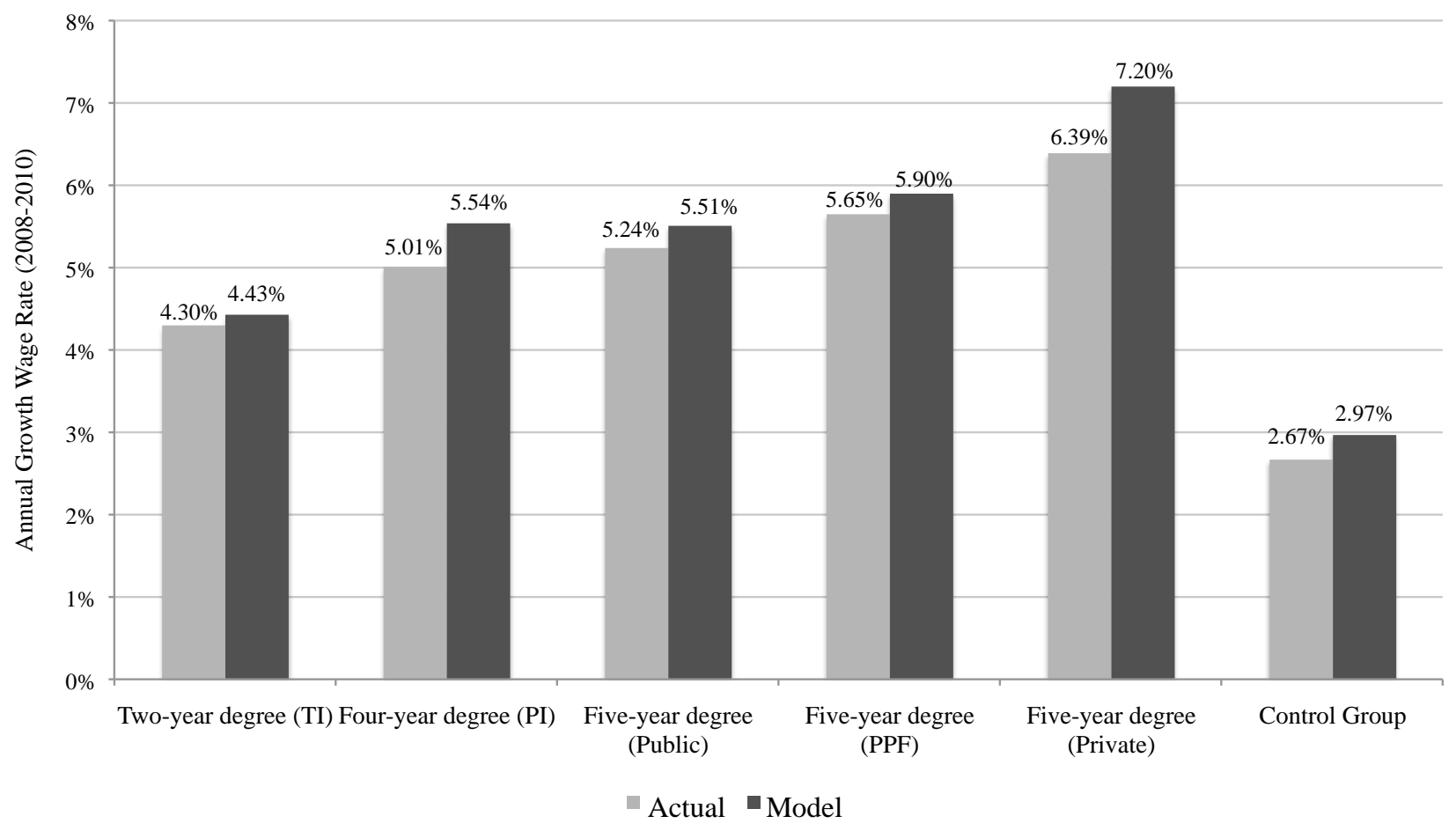

Notes: (a) Categories of institution types are defined as: Technical Institutes (TI), Professional Institutes (PI), Public Universities (Public), Private Universities with access to public funding (PPF) and Private Universities without public funding (Private). (b) Control Group corresponds to students who took PSU in 2007 but who do not appear in enrollment records (2008 and 2009). (c) The actual data (Actual) contains 57,159 observations while the simulated data (model) contains 100,000 observations generated from Model's estimates. 
Figure 9: Variance decomposition of test scores in measurement system

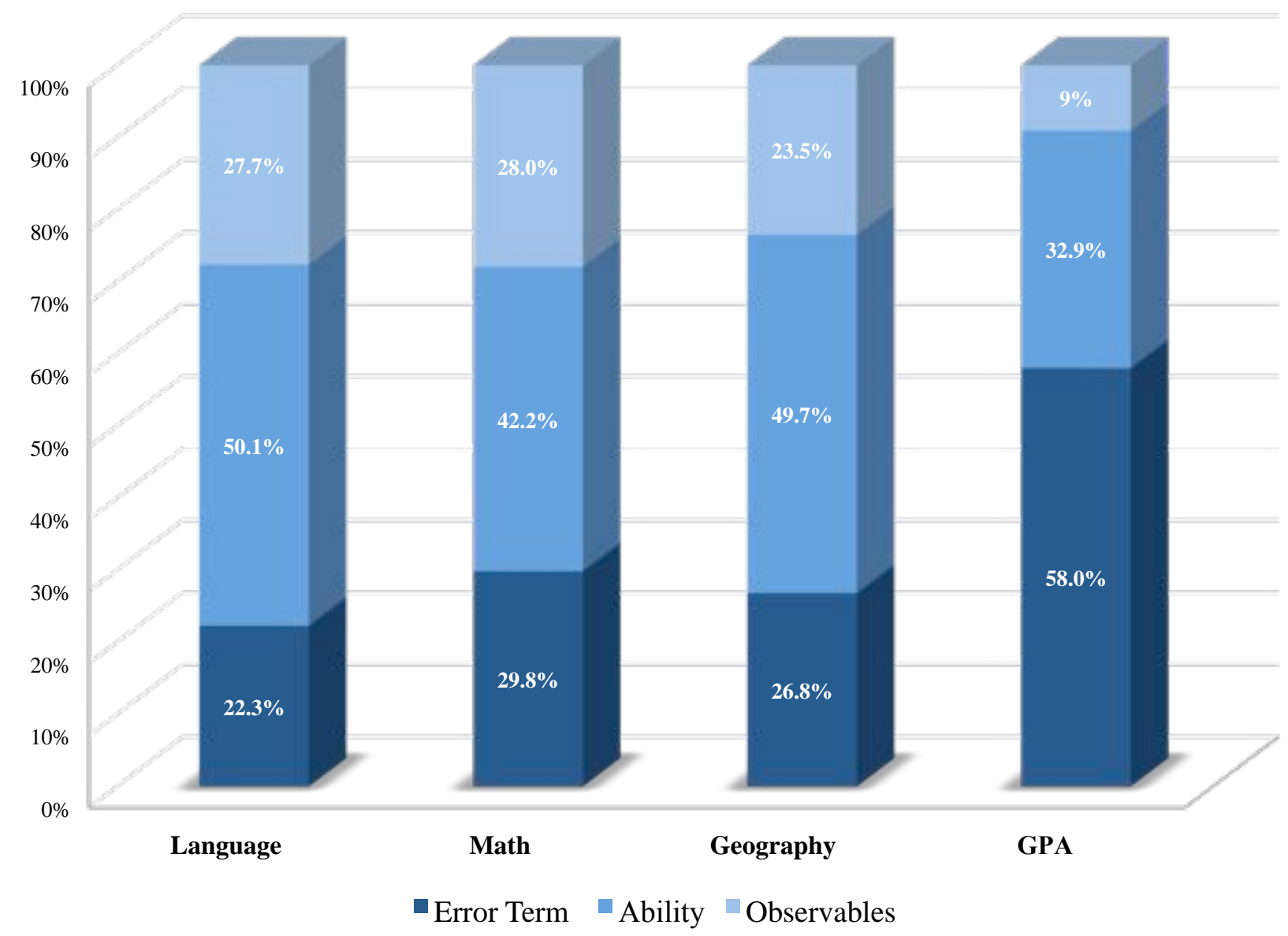

Notes: Bars indicate the percentage of the variance of test scores explained by observables $\left(X^{\prime} \beta\right)$, latent endowments $(\alpha \theta)$ and unobservables components $(\varepsilon)$. Tests scores include the subjects of Math, Language and Geography. 
Figure 10: Distribution of $\theta$ by type of degree

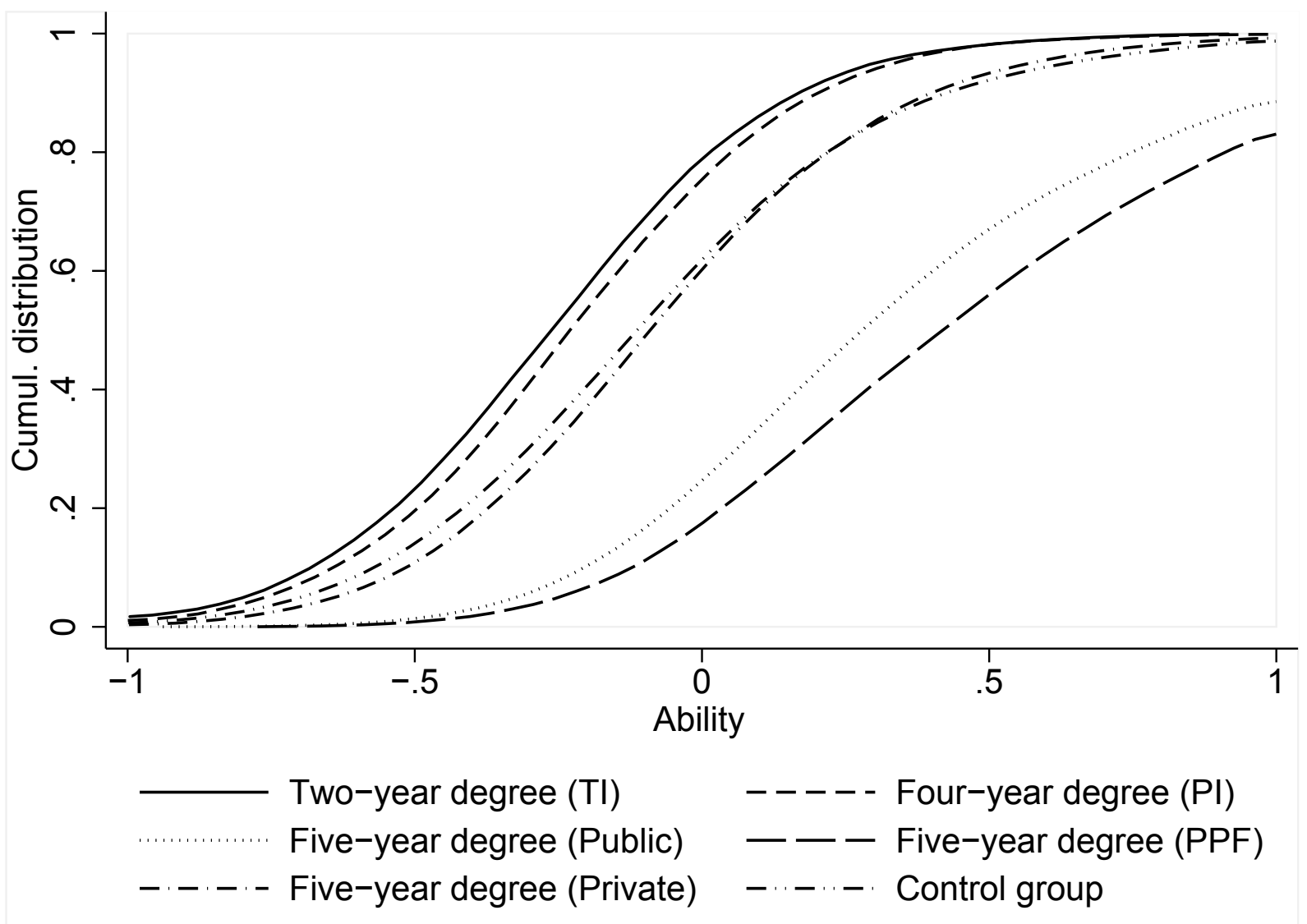

Notes: (a) Categories of institution types are defined as: Technical Institutes (TI), Professional Institutes (PI), Public Universities (Public), Private Universities with access to public funding (PPF) and Private Universities without public funding (Private). (b) Control Group corresponds to students who took PSU in 2007 but who do not appear in enrollment records (2008 and 2009). 
Figure 11: Distribution of average PSU score by type of degree

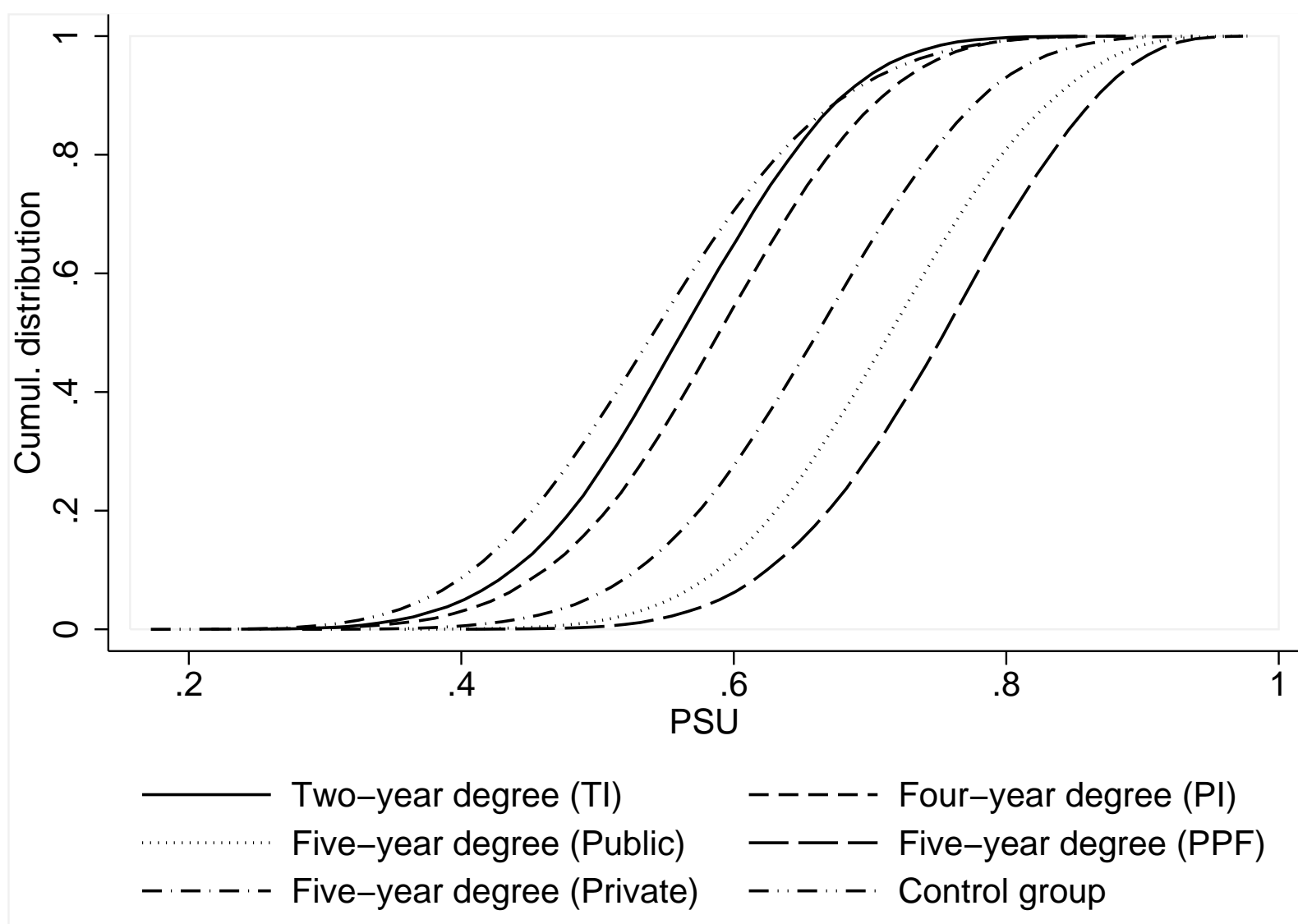

Notes: (a) Categories of institution types are defined as: Technical Institutes (TI), Professional Institutes (PI), Public Universities (Public), Private Universities with access to public funding (PPF) and Private Universities without public funding (Private). (b) Control Group corresponds to students who took PSU in 2007 but who do not appear in enrollment records (2008 and 2009). 
Figure 12: Earnings profiles by type of degree and institution

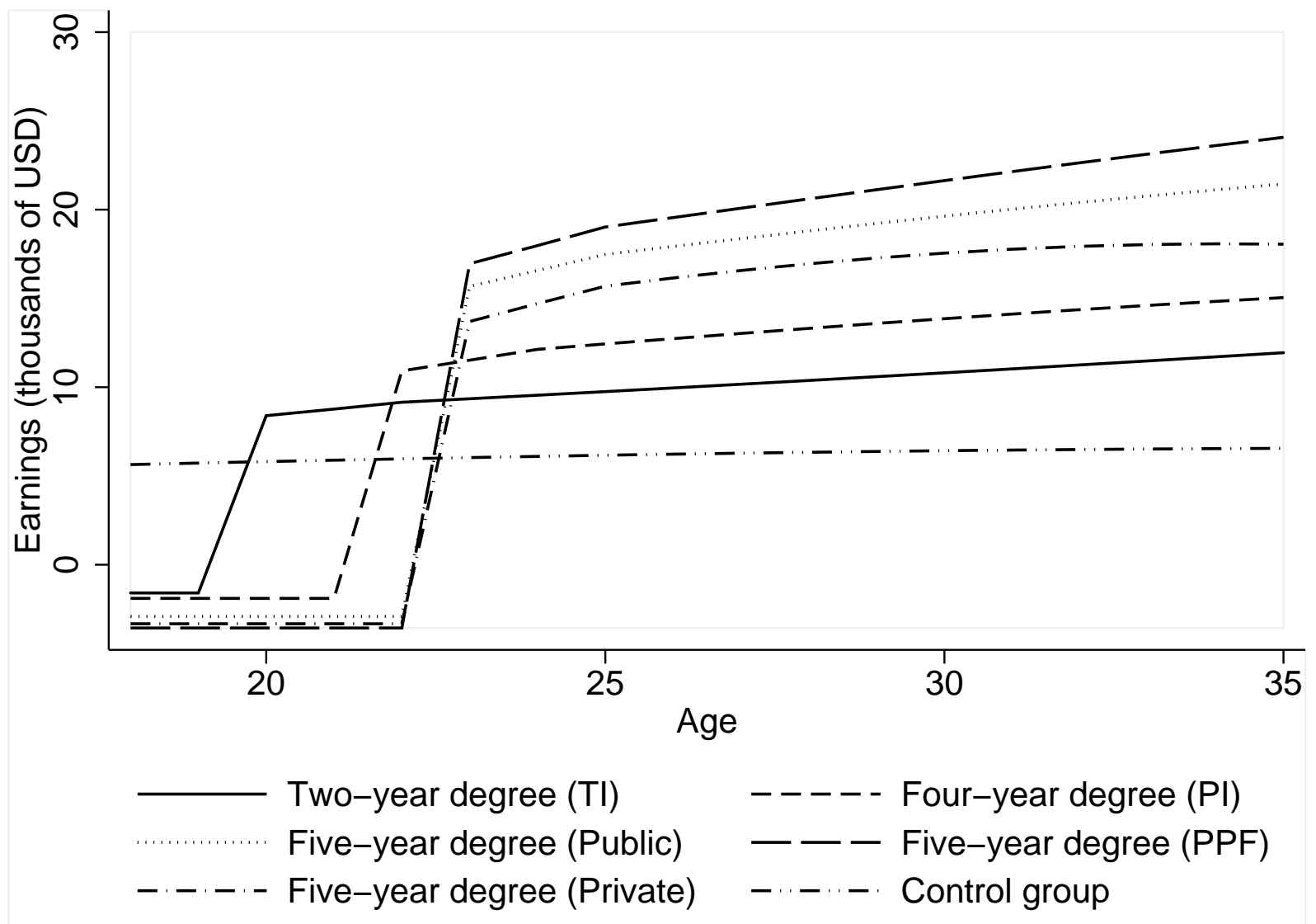

Notes: (a) We show estimates of $E\left[y_{j}(t) \mid D_{j}=1\right]$, where $y_{j}(t)$ correspond to annual earnings. (b) Categories of institution types are defined as: Technical Institutes (TI), Professional Institutes (PI), Public Universities (Public), Private Universities with access to public funding (PPF) and Private Universities without public funding (Private). (c) Control Group corresponds to students who took PSU in 2007 but who do not appear in enrollment records (2008 and 2009). 
Figure 13: Treatment on treated effects and unobserved heterogeneity (based on $\Delta_{j}^{0}$ )

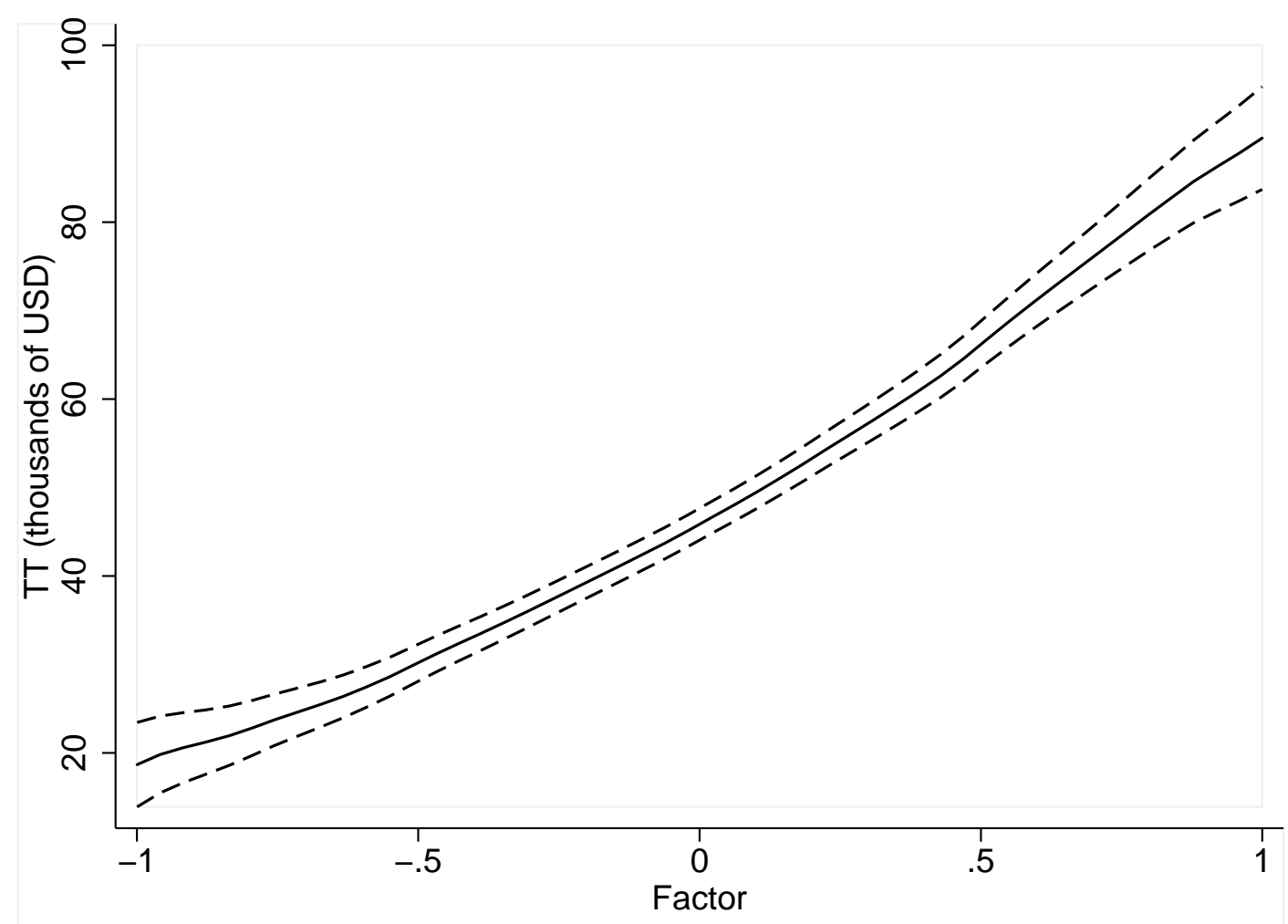

Notes: $\Delta_{j}^{0}$ corresponds to the financial benefits or losses (that is, excluding psychic costs or benefits) of choosing $j$ institution against earnings from the control group. Therefore, the present value of this choice is given by the following expression (see equations (8) and (9)):

$$
P V_{0}=\sum_{t=0}^{T} \frac{\hat{y}_{0}(t)}{(1+r)^{t}}
$$

Agent's economic benefits of postsecondary education are given by:

$$
\Delta_{j}^{0}=P V_{j}-P V_{0}
$$


Figure 14: Treatment on treated effects and unobserved heterogeneity (based on $\Delta_{j}^{k}$ )

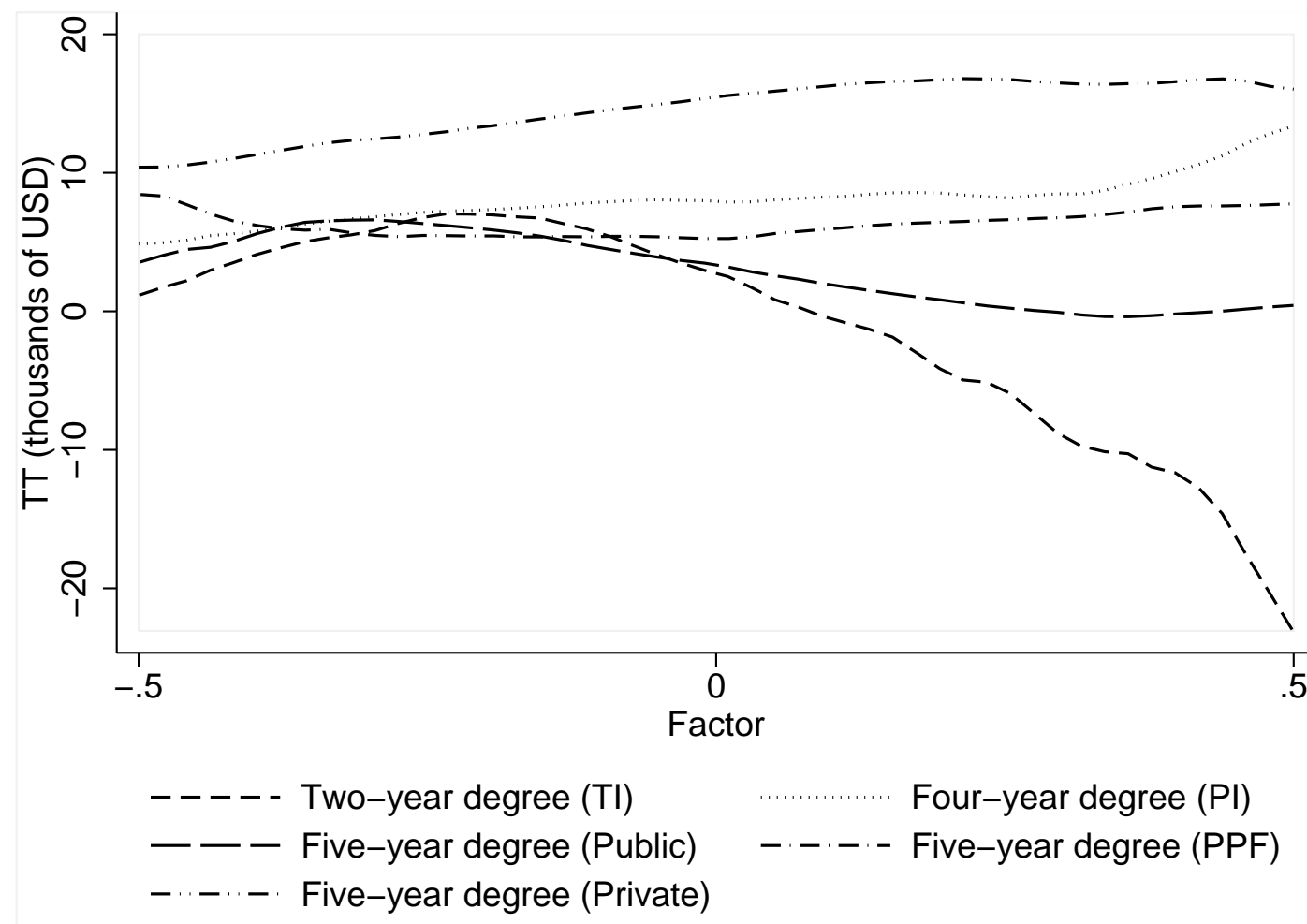

Notes: Categories of institution types are defined as: Technical Institutes (TI), Professional Institutes (PI), Public Universities (Public), Private Universities with access to public funding (PPF) and Private Universities without public funding (Private). (b) In this figure, we compare the first-best and the second-best choices. Let,

$$
\begin{aligned}
& j^{*}=\operatorname{argmax}_{j \in \mathcal{J}}\left\{V_{j}\right\} \\
& k^{*}=\operatorname{argmax}_{k \in \mathcal{J} \mid-j^{*}}\left\{V_{k}\right\}
\end{aligned}
$$

be the first and second choice, respectively. Then $D_{k \in \mathcal{J} \mid-j}=1$ if $k$ is the first choice in $\mathcal{J}$ excluding $j^{*}$. Let $P V_{j}$ and $P V_{k}$ the corresponding net economic benefits. Then:

$$
\begin{aligned}
\Delta_{j}^{k} & =P V_{j}-P V_{k} \\
r_{j}^{k} & =\left(P V_{j}-P V_{k}\right) / P V_{k}
\end{aligned}
$$




\section{A Appendix}

Table A.1: Goodness of Fit - Average Wages by Type of Institution

\begin{tabular}{|c|c|c|c|c|c|c|c|}
\hline & & $\overline{\mathrm{TI}}$ & PI & Public & $\mathrm{PPF}$ & Private & C. Group \\
\hline \multicolumn{8}{|l|}{ A. Means } \\
\hline & Actual & 12.151 & 12.307 & 12.577 & 12.642 & 12.377 & 11.866 \\
\hline & Model & 12.465 & 12.729 & 13.068 & 13.183 & 12.961 & 12.017 \\
\hline \multicolumn{8}{|l|}{ B. Standard Deviations } \\
\hline & Actual & 0.846 & 0.909 & 0.930 & 0.959 & 1.004 & 0.766 \\
\hline & Model & 0.860 & 0.909 & 0.892 & 0.892 & 0.919 & 0.838 \\
\hline C. Goodness of Fit Test (p-value) & & 0.0000 & 0.0000 & 0.0000 & 0.0000 & 0.0000 & 0.0000 \\
\hline
\end{tabular}

Notes: (a) Categories of institution types are define as: Two-year degrees provided by Technical Institutes (TI), four-year degrees obtained in Professional Institutes (PI) and five-year degrees from Public Universities (Public), Private with public funding Universities (PPF) and Private without public funding Universities (Private). (b) Control Group corresponds to those students who took PSU in 2007 but who do not appear in enrollment records (2008 and 2009). (c) Goodness of fit is tested using $\chi^{2}$ test where the Null Hypothesis is Model $=$ Data.

Table A.2: Goodness of Fit -Growth Wage Rate 2008-2010 by Type of Institution

\begin{tabular}{lr|cccccc}
\hline \hline \multirow{2}{*}{ A. Means } & & TI & PI & Public & PPF & Private & C. Group \\
& Actual & 0.043 & 0.050 & 0.052 & 0.056 & 0.063 & 0.026 \\
& Model & 0.044 & 0.055 & 0.055 & 0.059 & 0.072 & 0.029 \\
& & & & & & & \\
B. Standard Deviations & & & & & & & \\
& Actual & 0.074 & 0.078 & 0.077 & 0.076 & 0.085 & 0.075 \\
& Model & 0.082 & 0.081 & 0.079 & 0.081 & 0.087 & 0.076 \\
& & & & & & & \\
C. Goodness of Fit (p-value) & & 0.2056 & 0.0000 & 0.0001 & 0.0057 & 0.0000 & 0.0000 \\
\hline
\end{tabular}

Notes: (a) Categories of institution types are define as: Two-year degrees provided by Technical Institutes (TI), four-year degrees obtained in Professional Institutes (PI) and five-year degrees from Public Universities (Public), Private with public funding Universities (PPF) and Private without public funding Universities (Private). (b) Control Group corresponds to those students who took PSU in 2007 but who do not appear in enrollment records (2008 and 2009). (c) Goodness of fit is tested using $\chi^{2}$ test where the Null Hypothesis is Model $=$ Data. 
Table A.3: Goodness of Fit - Test Scores by Type of Institution

\begin{tabular}{|c|c|c|c|c|c|c|c|}
\hline \multicolumn{8}{|l|}{ A. Means } \\
\hline \multirow[t]{2}{*}{ Language } & Actual & 0.109 & 0.247 & 0.958 & 1.184 & 0.641 & 0.027 \\
\hline & Model & 0.159 & 0.277 & 0.899 & 1.113 & 0.627 & 0.059 \\
\hline \multirow[t]{2}{*}{ Math } & Actual & 0.066 & 0.227 & 1.147 & 1.561 & 0.687 & 0.008 \\
\hline & Model & 0.166 & 0.329 & 1.015 & 1.288 & 0.735 & 0.062 \\
\hline \multirow[t]{2}{*}{ Geography } & Actual & 0.152 & 0.257 & 0.987 & 1.195 & 0.629 & 0.080 \\
\hline & Model & 0.177 & 0.304 & 0.934 & 1.158 & 0.628 & 0.096 \\
\hline \multirow[t]{2}{*}{ NEM } & Actual & 0.617 & 0.623 & 1.289 & 1.390 & 0.833 & 0.469 \\
\hline & Model & 0.545 & 0.618 & 1.124 & 1.272 & 0.857 & 0.551 \\
\hline \multicolumn{8}{|c|}{ B. Standard Deviations } \\
\hline \multirow[t]{2}{*}{ Language } & Actual & 0.467 & 0.480 & 0.604 & 0.624 & 0.590 & 0.479 \\
\hline & Model & 0.481 & 0.489 & 0.565 & 0.600 & 0.527 & 0.521 \\
\hline \multirow[t]{2}{*}{ Math } & Actual & 0.475 & 0.535 & 0.863 & 0.962 & 0.771 & 0.430 \\
\hline & Model & 0.623 & 0.629 & 0.712 & 0.756 & 0.697 & 0.654 \\
\hline \multirow[t]{2}{*}{ Geography } & Actual & 0.445 & 0.453 & 0.731 & 0.749 & 0.628 & 0.502 \\
\hline & Model & 0.517 & 0.530 & 0.603 & 0.637 & 0.564 & 0.557 \\
\hline \multirow[t]{2}{*}{ NEM } & Actual & 0.506 & 0.505 & 0.686 & 0.720 & 0.564 & 0.496 \\
\hline & Model & 0.564 & 0.571 & 0.617 & 0.626 & 0.588 & 0.592 \\
\hline \multicolumn{8}{|c|}{ C. Goodness of Fit (p-value) } \\
\hline Language & & 0.0000 & 0.0000 & 0.0000 & 0.0000 & 0.0006 & 0.0000 \\
\hline Math & & 0.0000 & 0.0000 & 0.0000 & 0.0000 & 0.0000 & 0.0000 \\
\hline Geography & & 0.0004 & 0.0000 & 0.0000 & 0.0000 & 0.8386 & 0.0000 \\
\hline NEM & & 0.0000 & 0.3739 & 0.0000 & 0.0000 & 0.0000 & 0.0000 \\
\hline
\end{tabular}

Notes: (a) Categories of institution types are define as: Two-year degrees provided by Technical Institutes (TI), four-year degrees obtained in Professional Institutes (PI) and five-year degrees from Public Universities (Public), Private with public funding Universities (PPF) and Private without public funding Universities (Private). (b) Control Group corresponds to those students who took PSU in 2007 but who do not appear in enrollment records (2008 and 2009). (c) Goodness of fit is tested using $\chi^{2}$ test where the Null Hypothesis is Model = Data. 


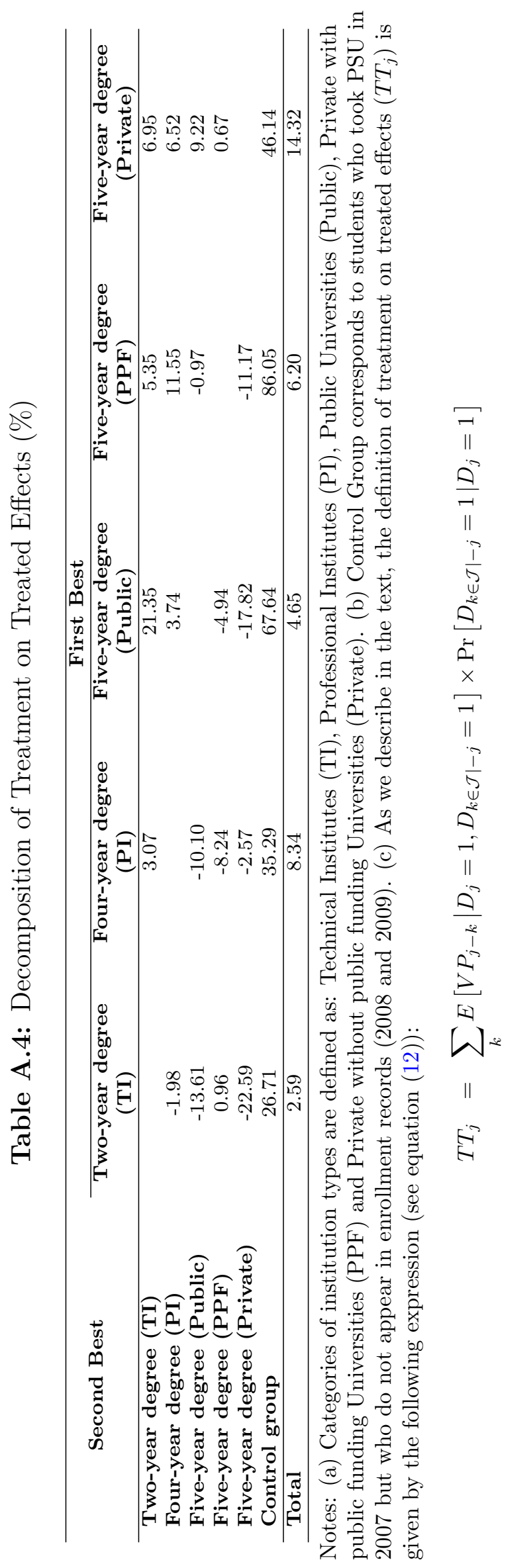

